Universidade de São Paulo

Instituto de Física

\title{
Propriedades eletrônicas de átomos e moléculas em fluidos supercríticos
}

\section{Marcelo Hidalgo Cardenuto}

Orientador: Prof. Dr. Sylvio Roberto Accioly Canuto

Tese de doutorado apre-
sentada ao Instituto de
Física para a obtenção do
título de Doutor Ciências

Banca examinadora:

Prof. Dr. Sylvio Roberto Accioly Canuto (IF/USP)

Prof. Dr. Marcio Teixeira do Nascimento Varella (IF/USP)

Prof. Dr. André de Pinho Vieira (IF/USP)

Prof. Dr. Puspitapallab Chaudhuri (UFAM)

Prof. Dr. Tertius Lima da Fonseca (UFG)

São Paulo, 2013 
FICHA CATALOGRÁFICA

Preparada pelo Serviço de Biblioteca e Informação do Instituto de Física da Universidade de São Paulo

\section{Cardenuto, Marcelo Hidalgo}

Propriedades eletrônicas de átomos e moléculas em fluidos supercríticos. - São Paulo, 2013.

Tese (Doutorado) - Universidade de São Paulo. Instituto de Física. Departamento de Física Geral.

Orientador: Prof. Dr. Sylvio Roberto Accioly Canuto

Área de Concentração: Física

Unitermos: 1. Efeito de solvente; 2. Fluidos supercríticos;

3. Espectro eletrônico; 4. Polarizabilidade. 


\section{Agradecimentos}

Agradeço primeiramente ao professor Sylvio Canuto por ter me recebido como seu aluno nesta etapa da minha formação profissional e pessoal. Agradeço toda a sua amizade e paciência durante a orientação deste trabalho de doutorado.

Agradeço a todos os colegas do grupo de física molecular e modelagem do IFUSP, a professora Kaline Coutinho, aos colegas Daniel, Paula, Ednilson e Herbert. Aos colegas que dividiram sala comigo; Rafael, Yoelvis, Rodrigo, Lucas, Carlos e Fernando. Ao ótimo trabalho realizado pelo Rafael e Lucas no cluster. Aos colegas do grupo de biofísica Antonio, Marcus, Evanildo e Cíntia e aos colegas que vieram em seguida fazer parte do grupo, George e Vinícius. Às colegas da secretaria, do Departamento de Física Geral, Dirce, Fátima e Silvana.

Agradeço aos meus pais por sempre me apoiarem e pela compreensão nos momentos de ausência.

À CAPES pelo apoio financeiro. 


\section{Resumo}

Neste trabalho apresentamos alguns estudos teóricos sobre propriedades eletrônicas de sistemas atômicos e moleculares em fase líquida e ambiente supercrítico. A utilização dos fluidos supercríticos têm atraído muito interesse como meio solvente para propriedades moleculares, reações químicas e são vistos como alternativa aos solventes orgânicos tóxicos. Assim como nos solventes convencionais, descrever suas propriedades por meio de estudos em nível molecular tem se tornado tão interessante quanto seu uso prático. Primeiramente realizamos o estudo da polarizabilidade estática do argônio e como esta propriedade se comporta em função da variação de pressão. Fizemos também um estudo deste sistema em torno do ponto crítico e região supercrítica. Dentro do intervalo de pressão que estudamos, não observamos variações significativas na polarizabilidade, embora no regime de baixas densidades este sistema apresentou certa dependência da polarizabilidade com a densidade. Neste estudo, também calculamos a constante dielétrica no ponto crítico. Em seguida estudamos o espectro de absorção do átomo de xenônio em ambiente formado por argônio líquido. Nesta parte, realizamos várias simulações com o objetivo de verificar o deslocamento da linha de absorção $5 p \rightarrow 6 s$ deste átomo em relação à densidade, explorando também as condições supercríticas. Observamos que o deslocamento do espectro ocorrido em meio solvente é para maiores energias (blue shift) à medida que a densidade aumenta, e obtemos bom acordo com os valores medidos. Por último, realizamos um estudo da mudança de um espectro eletrônico molecular onde o solvente é a água supercrítica. Utilizamos a molécula paranitroanilina como sonda solvatocrômica, e observamos que mesmo no regime de alta temperatura e baixa densidade ainda ocorre a formação de ligações de hidrogênio entre soluto e solvente. Obtemos um red shift para a transição eletrônica $\pi-\pi^{*}$ em água supercrítica. Este resultado é medido experimentalmente tanto para água em condições ambiente como em condição supercrítica, mas em água supercrítica o deslocamento é menor. Nosso resultado para a água supercrítica está em bom acordo com o resultado experimental e mostra que a maior contribuição para este deslocamento é devido ao efeito das interações eletrostáticas. Porém, ao compararmos os resultados da água em condições supercríticas com as condições normais de temperatura e pressão e o dióxido de carbono supercrítico como solventes, os resultados indicam que a aproximação de incluir apenas interações eletrostáticas é menos satisfatória e fornece somente parte do efeito de solvente.

Palavras-chave: efeitos de sovente, fluidos supercríticos, espectro eletrônico de absorção, polarizabilidade. 


\section{Abstract}

In this work we present some theoretical studies of the electronic properties of atomic and molecular systems in liquid and supercritical environments. The study of supercritical fluids is a interesting topic in solvent effects on molecular properties and chemical reactions. Their use can be an alternative to organic toxic solvents. Describing their molecular solvent properties, as opposite to conventional solvents, has become important as of pratical use. First we study the static polarizability of atomic argon and its behavior with pressure. The critical and near critical points also were considered in this study. In the range of pressures used, it is not observed significant changes in the polarizability, although the system present some dependence with density in the supercritical region. We have then determined the dielectric constant at the critical point. Next we study the absorption electronic spectra of xenon atom in liquid argon environment. In this part, we performed several simulations with the aim of verifying the density dependence of the spectral shift of the $5 p \rightarrow 6 s$ line of xenon. The supercritical region was also explored. We obtain the spectral blue shift in solvent environment for increasing density in good agreement with experiments. Finally, we study the electronic spectra of a solvatochromic probe molecule, the paranitroaniline, in supercritical water and supercritical carbon dioxide. We observe that even for high temperature hydrogen bond persists between the solute and the water molecules. A red shift in the $\pi-\pi^{*}$ transition of the electronic spectra of paranitroaniline is well described. This red shift is observed experimentally in water, but in supercritical water it is less pronounced. Our results for supercritical water is in good agreement with the experimental result and show that the long-range electrostatic contribution dominates the solute-solvente interaction and gives the largest influence in the calculated spectrum. Water in normal conditions and supercritical carbon dioxide were also considered for comparison and the results indicates that including only the electrostatic contribution is less satisfactory and gives only part of the total solvent effect.

Keywords: solvent effects, supercritical fluids, electronic absorption spectra, polarizability. 


\section{Lista de Abreviaturas}

$\begin{array}{ll}\text { Ar } & \text { Argônio } \\ \text { DFT } & \text { Density Functional Theory } \\ \text { ECP } & \text { Effective Core Potential } \\ \text { HB } & \text { Hydrogen Bond } \\ \text { HOMO } & \text { Highest Occupied Molecular Orbital } \\ \text { LUMO } & \text { Lowest Unoccupied Molecular Orbital } \\ \text { MC } & \text { Monte Carlo } \\ \text { PCM } & \text { Polarizable Continuum Model } \\ \text { PNA } & \text { Paranitroanilina } \\ \text { QM/MM } & \text { Quantum Mechanics/Molecular Mechanics } \\ \text { S-QM/MM } & \text { Sequential Quantum Mechanics/Molecular Mechanics } \\ \text { SPC/E } & \text { Extended Simple Point Charge Model } \\ \text { TDDFT } & \text { Time Dependent Density Functional Theory } \\ \text { Xe } & \text { Xenônio } \\ \text { Xe/Ar } & \text { Xenônio/Argônio }\end{array}$




\section{Sumário}

1 Introdução Geral 1

2 Simulação Clássica de Líquidos 5

2.1 Potencial interatômico . . . . . . . . . . . . . . 6

2.2 O Método Monte Carlo . . . . . . . . . . . . . . . . . . . . . 8

2.3 Função de distribuição radial de pares . . . . . . . . . . . . . . . . . 10

3 Métodos de Mecânica Quântica e Química Teórica 13

3.1 A aproximação de Hartree-Fock . . . . . . . . . . . . . . . . . . . . . 14

3.1.1 Funções base . . . . . . . . . . . . . . . . . . 16

3.2 Métodos pós-Hartree-Fock . . . . . . . . . . . . . . . 18

3.2 .1 Interação de configurações . . . . . . . . . . . . . . . 18

3.2.2 Teoria de perturbação de Møller Plesset . . . . . . . . . . . 19

3.2.3 Teoria do funcional da densidade . . . . . . . . . . . . . . 21

4 Método Sequencial QM/MM $\quad 25$

4.1 Análise estatística das configurações . . . . . . . . . . . . 26

4.2 Análise estrutural . . . . . . . . . . . . . . . . . . . . . . . 28

5 Polarizabilidade do Argônio Líquido $\quad 29$

5.1 Detalhes da simulação e cálculos . . . . . . . . . . . . . . . . . . 31

5.2 Cálculo da polarizabilidade . . . . . . . . . . . . . . 33 
5.3 Polarizabilidade em torno do ponto crítico e condição supercrítica . . 36

6 Espectro Eletrônico do Átomo de Xenônio em Argônio 39

6.1 Simulação clássica Monte Carlo . . . . . . . . . . . . . . . . . 40

6.2 Camadas de solvatação . . . . . . . . . . . . . . . . . . . 41

6.3 Cálculo do espectro eletrônico . . . . . . . . . . . . . . . . . 43

7 Espectro Eletrônico da Paranitroanilina em Fluido Supercrítico: $\mathrm{H}_{2} \mathrm{O}$ e $\mathrm{CO}_{2} \quad 51$

7.1 PNA em água supercrítica e água normal . . . . . . . . . . . . . . 51

7.1.1 Simulação em água supercrítica e normal . . . . . . . . . . . 53

7.1.2 Estatística das ligações de hidrogênio . . . . . . . . . . 57

7.1.3 Espectro eletrônico da PNA . . . . . . . . . . . . . 61

7.2 PNA em $\mathrm{CO}_{2}$ supercrítico . . . . . . . . . . . . . . . 68

7.2.1 Simulação MC da PNA em $\mathrm{CO}_{2}$ supercrítico . . . . . . . . . . 69

7.2.2 Espectro da PNA em $\mathrm{CO}_{2}$ supercrítico . . . . . . . . . . 72

8 Conclusões $\quad 77$

$\begin{array}{ll}\text { Referências Bibliográficas } & 80\end{array}$ 


\section{Capítulo 1}

\section{Introdução Geral}

A busca por uma interpretação dos fenômenos e propriedades atômicas e moleculares observadas em meio líquido é de grande interesse nas áreas de física, química e biologia. Reações químicas, propriedades estruturais e espectroscópicas de moléculas são sensíveis ao meio solvente [1], devido às interações intermoleculares. Ao longo das útlimas décadas, foram desenvolvidos métodos e modelos teóricos com o objetivo de estudar os efeitos do solvente nas propriedades eletrônicas de sistemas atômicos e moleculares. Os trabalhos pioneiros de Onsager [2] e Kirkwood [3] deram origem aos modelos de solvente contínuo dos quais podemos citar o modelo contínuo polarizável (PCM -Polarizable Continuum Model) $[4,5,6]$. É um modelo onde podem ser utilizados métodos de mecânica quântica sofisticados, mas que as interações locais específicas entre soluto e solvente não são consideradas explicitamente. Propriedades termodinâmicas como temperatura e pressão também não são especificadas no modelo, e uma constante dielétrica caracteriza macroscopicamente o meio de forma simplificada. Outra opção para o estudo de efeitos de solvente são os métodos híbridos, que combinam métodos de mecânica molecular (simulação clássica) de líquidos e cálculos de mecânica quântica $[7,8,9]$ chamados de métodos QM/MM (Quantum Mechanics/Molecular Mechanics). A principal diferença entre 
estes métodos e o de solvente contínuo, é que o QM/MM considera explicitamente as moléculas do solvente. O uso de métodos híbridos é uma alternativa que nos permite aplicar diferentes níveis de teoria às diferentes partes do sistema. A proposta do método QM/MM é aplicar métodos de simulação clássica em uma parte que contém a maior quantidade de átomos, que geralmente trata-se do solvente. Os cálculos quânticos são aplicados na parte de menor tamanho, que é o alvo do estudo das propriedades de estrutura eletrônica no sistema. O método híbrido sequencial (S-QM/MM) proposto por Canuto e Coutinho [10, 11] é uma variante do QM/MM convencional e mais detalhes são expostos no capítulo 4.

Uma classe de solventes bastante utilizada é a dos fluidos supercríticos (SCFs - Supercritical Fluids). O termo supercrítico é usado para substâncias que estejam acima de sua temperatura crítica $T_{c}$, algumas vezes usa-se o par termodinâmico temperatura e pressão $\left(T_{c}\right.$ e $\left.P_{c}\right)$ para definir a condição supercrítica de uma substância. A sua utilização como meio alternativo aos solventes tóxicos e nocivos ao meio ambiente fez surgir o termo "química verde"(green chemistry) [1, 12] e tem sido utilizado para várias finalidades na indústria química, farmacêutica e alimentícia $[13,14]$. Duas substâncias muito utilizadas como solvente supercrítico são a água e o dióxido de carbono $\left(\mathrm{CO}_{2}\right)$. Ambos são substâncias não tóxicas, não inflamáveis, de baixo custo e fácil obtenção. A condição supercrítica do $\mathrm{CO}_{2}$ é bem acessível experimentalmente, pois seu ponto crítico é relativamente baixo, em torno de $31^{\circ} \mathrm{C}$ e $73 \mathrm{~atm}$, em relação aos valores da água $\left(374^{\circ} \mathrm{C}, 220 \mathrm{~atm}\right)$. Maiores detalhes sobre fluidos supercríticos podem ser encontrados em $[12,15,16,17]$ e no livro de Reichardt sobre efeitos de solvente, no qual foi incluído em sua última edição um capítulo sobre química verde de solventes [1].

Apresentamos nesta tese um estudo sobre sistemas atômicos e moleculares sob efeitos do meio solvente, explorando com especial ênfase as condições termodinâmicas da região supercrítica. Consideramos a região supercrítica aquela onde o par de 
variáveis termodinâmicas, temperatura e pressão $(T, P)$ estejam além dos valores críticos $\left(T_{c}\right.$ e $\left.P_{c}\right)$ da substância.

Primeiramente estudamos a polarizabilidade atômica do argônio líquido. Em um trabalho anterior, Canuto e Coutinho $[18,19]$ determinaram a polarizabilidade deste sistema, obtendo também a constante dielétrica do argônio líquido. Aqui, nos propusemos a investigar o comportamento da polarizabilidade deste mesmo sistema sujeito a variações na pressão. Entramos também nos regimes de baixas densidades e em torno do ponto crítico, buscando verificar o comportamento da polarizabilidade em outras condições termodinâmicas aplicadas a este líquido atômico. A partir da polarizabilidade obtivemos teoricamente pela primeira vez a constante dielétrica do argônio no ponto crítico.

Em seguida apresentamos um estudo do espectro atômico de absorção do átomo de xenônio $(X e)$ em ambiente formado por argônio $(A r)$. Esta é uma situação bastante peculiar, pois trata de um átomo inerte em um líquido formado também por átomos inertes (gás nobre). Realizamos uma série de simulações sob diferentes condições termodinâmicas incluindo o regime supercrítico. Aplicando a metodologia S-QM/MM, pudemos calcular o espectro atômico do Xe e verificar o comportamento do desvio ou shift solvatocrômico em relação às variações de densidade do meio solvente. O desvio que pretendemos obter é sempre o do átomo sob efeito do meio em relação ao átomo isolado. Este é um problema muito interessante, visto que se trata de um sistema atômico, onde temos um soluto sem momentos eletrostáticos em ambiente formado por solvente também sem momentos eletrostáticos, um problema onde as interações de dispersão são importantes. Por muitos anos a descrição teórica do deslocamento espectral em função da densidade ficou em aberto. Neste estudo descrevemos este deslocamento desde o regime de baixas até altas densidades, incluindo situações que correspondem ao regime supercrítico.

Em um estudo seguinte consideramos sistemas moleculares. Estudamos o espec- 
tro eletrônico da molécula paranitroanilina (PNA) em água supercrítica. Esta molécula possui uma estrutura simples entre uma classe de moléculas muito estudadas por suas propriedades de ótica não linear [20]. Escolhemos a PNA como molécula de prova para estudar seu espectro em água supercrítica, um procedimento bem usado não só em solventes convencionais, mas também em supercríticos [21, 22, 23, 24, 25]. A PNA apresenta em sua estrutura dois grupos onde podem ocorrer a formação de ligações de hidrogênio, isto tem motivado uma série de trabalhos justamente para se discutir se estas ligações ocorrem também na água supercrítica [26, 27, 28, 29] e entre solutos e a água supercrítica [30, 31, 32]. Estudamos a formação de ligações de hidrogênio e o espectro da PNA em água supercrítica e em água nas condições normais de temperatura e pressão (água normal), fazendo a comparação das duas situações. Em seguida estudamos como estas ligações de hidrogênio afetam o espectro de absorção na região UV-Vis (ultravioleta visível). Dando prosseguimento, apresentamos resultados do espectro da PNA também em $\mathrm{CO}_{2}$ supercrítico, outra substância muito estudada ultimamente no campo dos fluidos supercríticos. As conclusões que obtivemos sobre os resultados são apresentadas num breve sumário ao final dos capítulos e, no final, são reunidas e apresentadas num capítulo de conclusão geral. 


\section{Capítulo 2}

\section{Simulação Clássica de Líquidos}

O estudo de sistemas líquidos e sua influência nas propriedades de sistemas atômicos e moleculares têm apresentado muitos avanços nas últimas décadas. Isto se deve ao desenvolvimento nas áreas de simulação computacional e das teorias e modelos propostos para estudar os líquidos. Verifica-se experimentalmente que propriedades eletrônicas de átomos apresentam mudanças quando estudadas em fase gasosa ou fase líquida. De maneira geral, as causas destas modificações são chamadas de efeitos de solvente, cujo objetivo de estudo está fortemente ligado aos modelos de sistemas líquidos.

Nos modelos de solvente contínuo o líquido não tem estrutura, isto é, não existem moléculas constituindo o líquido e este é tratado como um dielétrico contínuo [5]. A molécula que é objetivo de estudo neste meio solvente é localizada em uma cavidade dentro do dielétrico, no qual é atribuído um valor para sua constante dielétrica. Algumas variantes do modelo contínuo propõem diferentes formas para a cavidade [5]. Neste modelo não são consideradas as interações intermoleculares explícitas como, por exemplo, as interações do tipo ligação de hidrogênio entre soluto e solvente.

A necessidade de incluir moléculas explícitas levou ao desenvolvimento dos chamados modelos discretos do solvente. Estes consideram que o líquido é constituído 
por suas moléculas explicitamente e portanto, as formas das interações intermoleculares devem ser conhecidas, ou pelo menos aproximadamente conhecidas na forma de um potencial interatômico, como apresentado na seção 2.1. A utilização dos modelos discretos se dá por meio das simulações computacionais, e os dois métodos de simulação muito utilizados são: a dinâmica molecular e o método Monte Carlo, este último será apresentado de forma breve na seção 2.2 .

Os métodos de simulação clássica citados no final do parágrafo acima não descrevem detalhes dos fenômenos relacionados à estrutura eletrônica das moléculas e átomos. Aplicar estes métodos junto aos cálculos de mecânica quântica de diversos níveis de aproximação é a proposta do métodos híbridos QM/MM citados na introdução. O método híbrido S-QM/MM que é usado nesta tese será apresentado posteriormente (capítulo 4).

\section{$2.1 \quad$ Potencial interatômico}

Uma das informações que devemos ter ao estudar um sistema de muitas partículas é a do potencial de interação entre estas partículas. Esse potencial pode ser obtido resolvendo a equação de Schrödinger, mas torna-se difícil para sistemas de muitas partículas, como é o caso dos sistemas líquidos. Assim, utilizam-se os potenciais analíticos parametrizados. Este potencial nos fornece a maneira na qual os átomos ou moléculas interagem com os seus vizinhos. Com o objetivo de tratar sistemas em fase líquida e do ponto de vista clássico, uma boa aproximação é tomar apenas o termo que descreve a soma sobre a interação entre pares de partículas. Um potencial frequentemente usado em simulação de sistemas em fase líquida é o potencial de Lennard-Jones, que tem a seguinte forma analítica [33]

$$
U^{L J}\left(r_{i j}\right)=4 \varepsilon_{i j}\left[\left(\frac{\sigma_{i j}}{r_{i j}}\right)^{12}-\left(\frac{\sigma_{i j}}{r_{i j}}\right)^{6}\right]
$$


mais o termo devido à interação de Coulomb

$$
U^{C}\left(r_{i j}\right)=\frac{q_{i} q_{j}}{4 \pi \epsilon r_{i j}}
$$

onde $r_{i j}$ é a distância entre as partículas interagentes, $\sigma$ e $\varepsilon$ são parâmetros do potencial com a combinação para pares atômicos dada pelas expressões

$$
\varepsilon_{i j}=\left(\varepsilon_{i} \varepsilon_{j}\right)^{1 / 2} \quad \text { e } \quad \sigma_{i j}=\left(\sigma_{i} \sigma_{j}\right)^{1 / 2}
$$

que são relações utilizadas quando os átomos são diferentes. A figura 2.1 mostra a curva que representa o potencial de Lennard-Jones. O parâmetro $\varepsilon$ é a energia de ligação e $\sigma$ é a distância entre os sítios (posições dos átomos) na qual o potencial é nulo, sendo que para $r<\sigma$ o potencial é altamente repulsivo, não permitindo a superposição da partículas.

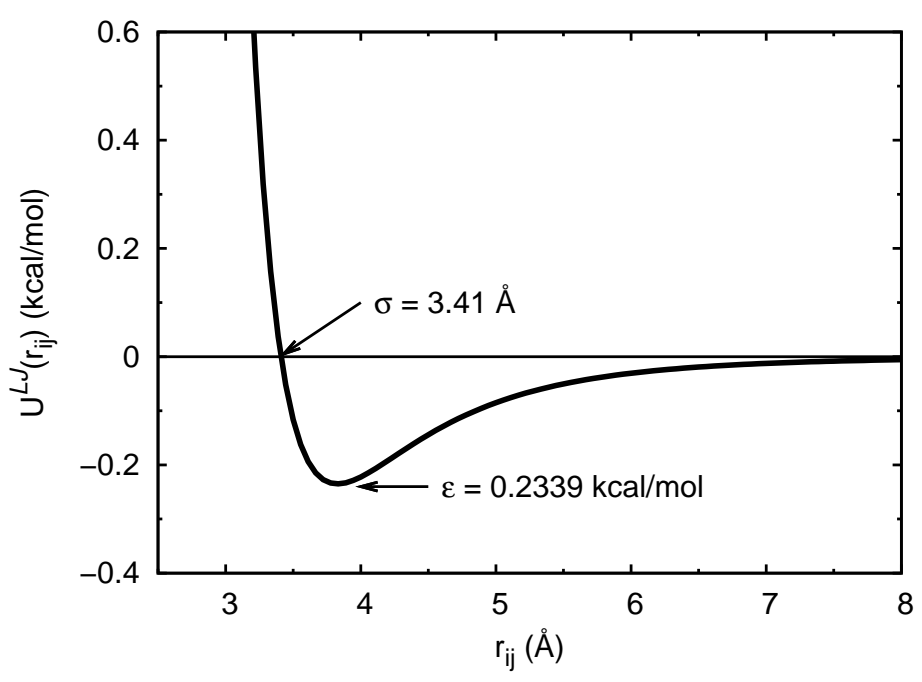

Figura 2.1: Forma da curva de interação interatômica do potencial de LennardJones. Os parâmetros $\sigma$ e $\varepsilon$ são dados nas referências [73, 86].

A simulação computacional torna possível uma investigação teórica dos líquidos 
atômicos e moleculares. Dois métodos são amplamente utilizados e bem estabelecidos: o método de dinâmica molecular e o método Monte Carlo [33]. O método de Monte Carlo permite que se obtenha configurações do líquido que sejam acessíveis com uma certa probabilidade, ou seja, é um método estatístico. A probabilidade de que essas configurações ocorram é dada pelo peso ou fator de Boltzmann, garantindo depois que possamos obter as propriedades de interesse como médias estatísticas simples, desde que o sistema tenha atingido o equilíbrio termodinâmico. Neste trabalho, o método de Monte Carlo é utilizado para realizar as simulações do líquido. Na próxima seção apresentamos alguns detalhes sobre este método.

\subsection{O Método Monte Carlo}

Um dos objetivos de uma simulação de sistemas líquidos é obter a estrutura do líquido, ou seja, como estão organizados os seus átomos ou moléculas em uma certa região. Utilizamos uma caixa de simulação, e o arranjo espacial dos átomos ou moléculas do líquido dentro da caixa é o que chamamos de configuração. Numa simulação computacional destinada a obter as propriedades do líquido, são necessárias muitas dessas configurações.

A função de partição de um sistema descrito pelo hamiltoniano $\mathcal{H}(\mathrm{r}, \mathrm{p})$ é [33]

$$
Z=\iint e^{-\mathcal{H} / k T} d r d p
$$

Assumindo a separação das partes cinética e configuracional nesta integral [34], temos que a média de uma grandeza para um número finito de configurações é dada por

$$
\langle F\rangle=\lim _{N \rightarrow \infty} \frac{\sum_{i=1}^{N} F(r) e^{(-U(r) / k T)}}{\sum_{i=1}^{N} e^{(-U(r) / k T)}}
$$


onde $U(r)$ é o potencial de interação. Para evitar que configurações pouco prováveis venham a ser usadas no cálculo de médias, utiliza-se o método de amostragem de Metropolis [33, 35], que consiste em escolher configurações com probabilidade dada pelo fator de Boltzmann

$$
e^{(-U / k T)}
$$

Dada uma configuração inicial aleatória, um conjunto de configurações é obtido e a transição de uma configuração para outra acontece com probabilidade que obedece a um processo markoviano [33], onde cada configuração gerada depende apenas daquela que a precede. O algoritmo de amostragem de Metrópolis é utilizado no critério de aceitação ou rejeição do movimento de partículas e é baseado na diferença de energia $\Delta U$ entre as configurações. Na prática o algoritmo de Metrópolis segue as seguintes etapas:

1. Parte-se de uma configuração inicial;

2. Uma nova configuração aleatória é gerada;

3. A diferença de energia entre as configurações é calculada;

4. Se $\Delta U<0$, a nova configuração é aceita, e retorna-se ao passo 2 ;

5. Se $\Delta U>0$, o movimento é permitido com probabilidade $\exp (-\Delta U / k T)$ e é gerado um número aleatório $p$ entre 0 e 1;

6. Se $p<\exp (-\Delta U / k T)$, a nova configuração é aceita e retorna-se ao passo 2 ;

7. Se $p>\exp (-\Delta U / k T)$, a configuração atual é mantida e retorna-se ao passo 2

Como o peso probabilístico de ocorrência das configurações é dado pelo fator de Boltzmann, as propriedades termodinâmicas do sistema são obtidas como médias simples, e para um número $\mathrm{N}$ de configurações o valor médio será

$$
\langle F\rangle=\frac{1}{N} \sum_{i=1}^{N} F_{i}
$$


O erro devido ao tamanho finito do número de configurações na simulação é dado por

$$
\sigma=\sqrt{\frac{1}{N-1}\left\langle\delta F^{2}\right\rangle}
$$

onde

$$
\left\langle\delta F^{2}\right\rangle=\frac{1}{N} \sum_{i=1}^{N}\left(F_{i}-\langle F\rangle\right)^{2}=\left\langle F^{2}\right\rangle-\langle F\rangle^{2}
$$

é a variância de $F$ e N é o número de configurações.

Em uma simulação cada configuração contém um número limitado de átomos dentro da caixa, que tem dimensões e número de átomos bem menor que um sistema real. Os átomos que se encontram em regiões mais internas da caixa interagem entre si, mas à medida em que se aproximam das bordas, encontram um ambiente diferente e com menos moléculas para interagir, dando origem aos efeitos de borda. Para evitar este efeito, condições periódicas de contorno são utilizadas. Neste esquema, são consideradas réplicas da caixa de simulação que se repetem em todas as direções (figura 2.2). Com o método de imagens, os átomos nas bordas da caixa interagem com átomos de uma caixa vizinha e um raio de corte para a interação é definido para que o átomo não tenha interação com um outro átomo e sua réplica ao mesmo tempo. O procedimento geralmente usado é ter o raio de corte definido como metade da aresta da caixa.

\subsection{Função de distribuição radial de pares}

As propriedades estruturais do líquido são obtidas através da função de distribuição radial de pares. A função g(r) é definida como a integral da parte configuracional sobre todos os átomos, exceto dois, que estão distantes de uma distância $r$ um do outro, e é dada pela expressão

$$
g\left(\boldsymbol{r}_{1}, \boldsymbol{r}_{2}\right)=\frac{N(N-1)}{\rho^{2} Z} \int e^{-U / k T} d \boldsymbol{r}_{3} d \boldsymbol{r}_{4} \ldots d \boldsymbol{r}_{N}
$$




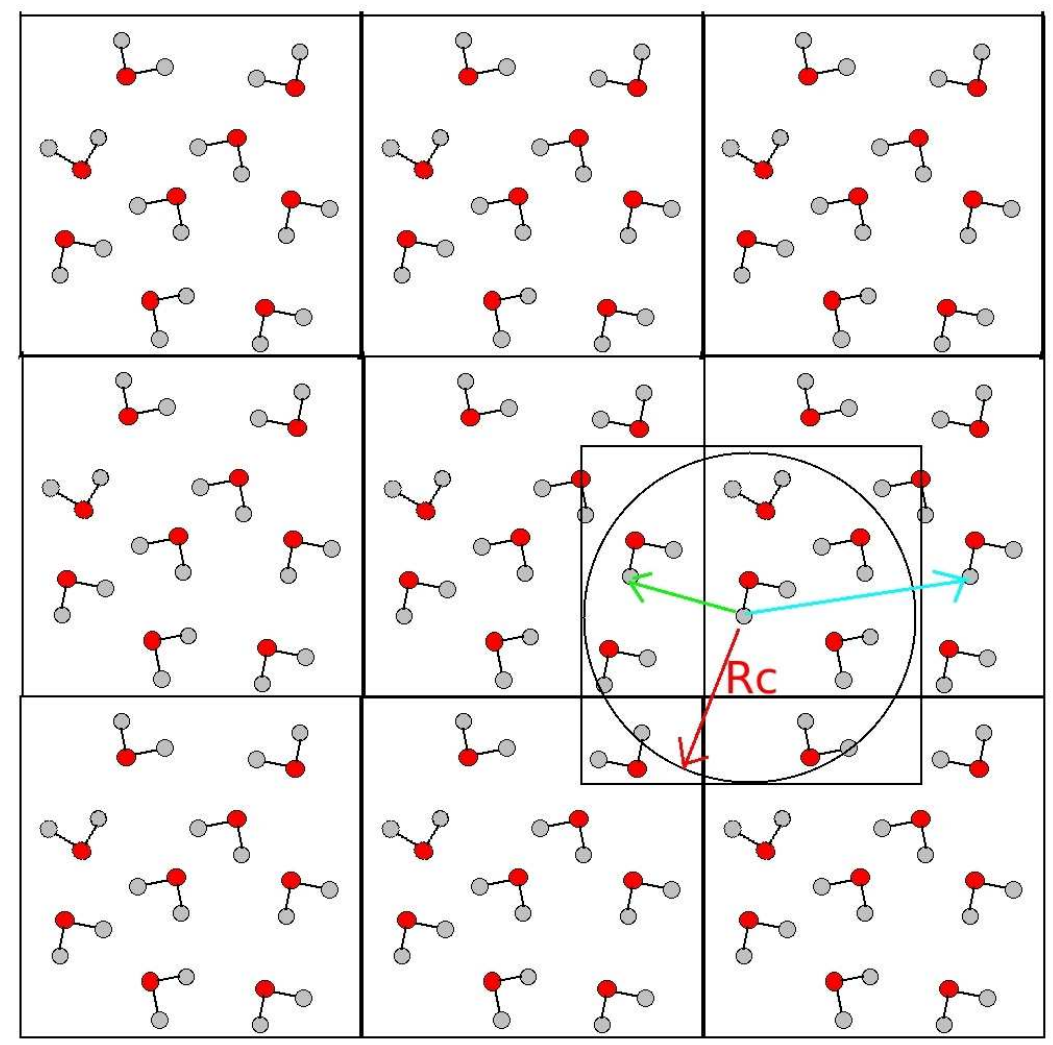

Figura 2.2: Representação bidimensional da caixa de simulação (no centro) e as réplicas introduzindo as condições periódicas de contorno. Como exemplo, a figura mostra a interação entre os átomos distantes (em verde) por uma distância menor que um raio de corte $R c$ (em vermelho). A interação não ocorre com a molécula imagem (em azul) que está além do raio de corte.

A função g(r) nos dá informação sobre a estrutura em volta de um átomo de referência. Uma estrutura de camadas pode ser observada no gráfico de uma g(r), permitindo que se faça uma análise para determinar como está ordenado o meio que envolve o átomo ou molécula de referência. Integrando a expressão para a g(r) ao longo de uma camada esférica, obtemos o número de átomos em torno do átomo de referência, esta quantidade é chamada de número de coordenação, definido por

$$
N(r)=4 \pi \frac{N}{V} \int_{0}^{r} g(r) r^{2} d r
$$


Experimentalmente a função de distribuição radial pode ser determinada através de espalhamento de raio-X [36, 37] e de neutrons [38]. Na figura 2.3 temos a representação esquemática de uma típica $\mathrm{g}(\mathrm{r})$ de um sistema atômico em fase líquida [39]. Vê-se que $g(r) \rightarrow 0$ quando $r \rightarrow 0$, caso contrário os átomos estariam se sobrepondo, e $g(r) \rightarrow 1$ quando $g(r) \rightarrow \infty$ indicando que a grandes distâncias (da ordem de alguns diâmetros atômicos) a estrutura em relação ao átomo de referência, apresenta-se desordenada tendendo a uma distribuição de gás ideal.

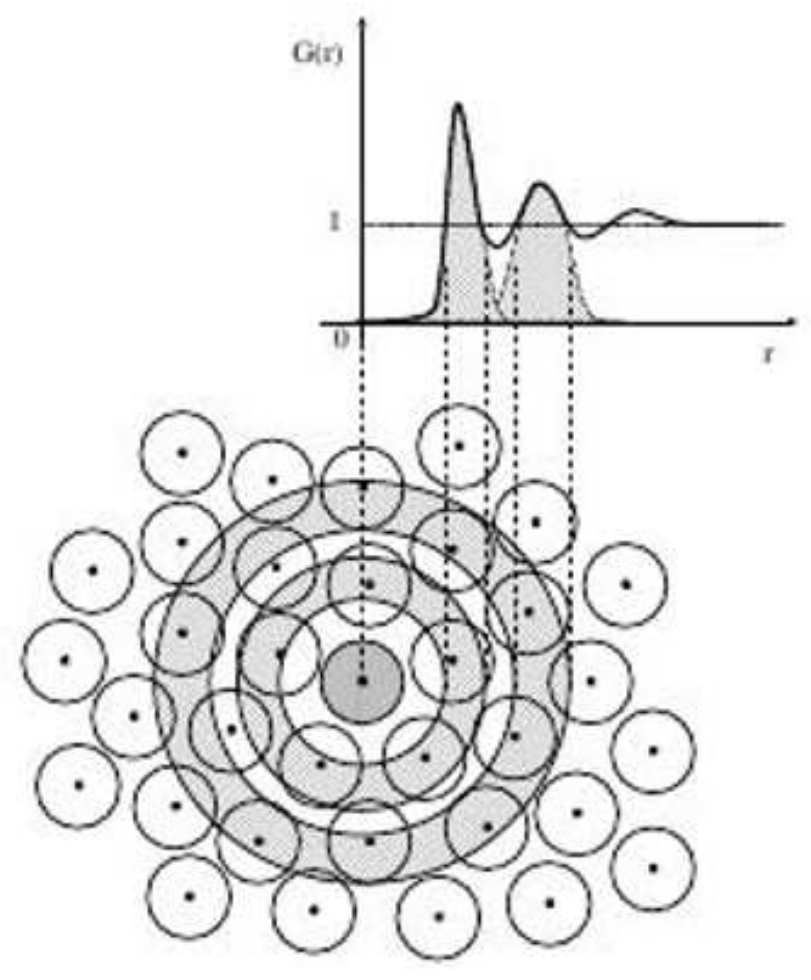

Figura 2.3: Representação esquemática da $g(r)$. A região dos picos representam a estrutura de camadas em volta do átomo de referência. A integração abaixo da curva em cada pico dá o número médio de átomos na camada. Figura extraída da referência [39]. 


\section{Capítulo 3}

\section{Métodos de Mecânica Quântica e Química Teórica}

Neste capítulo apresentamos alguns dos métodos utilizados no estudo da estrutura eletrônica de sistemas atômicos e moleculares. Primeiramente será sucintamente apresentado o método de Hartree-Fock (HF), que é utilizado como ponto de partida para outras aproximações para a solução da equação de Schrödinger em problemas de estrutura eletrônica de átomos e moléculas. Em seguida, descrevemos as principais características de alguns dos métodos chamados pós-Hartree-Fock que são conhecidos por ter como objetivo incluir parte da correlação eletrônica, inexistente na aproximação de Hartree-Fock. Terminamos o capítulo apresentando a teoria do funcional da densidade (DFT). Maiores detalhes sobre estes métodos são descritos na literatura sobre mecânica quântica aplicada à química teórica [40, 41, 34, 42, 43]. 


\subsection{A aproximação de Hartree-Fock}

Os métodos utilizados no estudo da estrutura eletrônica de átomos e moléculas têm por objetivo resolver a equação de Schrödinger

$$
\hat{H} \Psi=E \Psi
$$

cuja solução para sistemas de vários elétrons deve ser obtida por métodos aproximados. Em sistemas moleculares, uma primeira aproximação é feita com relação ao movimento de núcleos e elétrons, a aproximação de Born-Oppenheimer [44], onde se admite que os elétrons experimentam um campo de núcleos estacionários. Isto torna possível obter e resolver separadamente uma equação para os elétrons, onde o operador hamiltoniano tem a seguinte forma (em unidades atômicas)

$$
\hat{\boldsymbol{H}}=-\sum_{i=1}^{N} \frac{1}{2} \nabla_{i}^{2}-\sum_{i, A}^{N, M} \frac{Z_{A}}{\boldsymbol{r}_{i A}}+\sum_{i, j}^{N} \frac{1}{\boldsymbol{r}_{i j}}
$$

onde o primeiro termo representa a energia cinética de cada elétron (indexados pela letra $i$ ), o segundo termo é a interação entre elétrons e núcleos (indexados pela letra $A$ ) e o último termo representa a interação entre elétrons. A função de onda multieletrônica deve satisfazer a propriedade de antissimetria com relação à troca de coordenadas de quaisquer dois elétrons. Para que se obedeça esta propriedade, a função de onda é escrita na forma de um determinante de Slater [45] mostrado abaixo

$$
\Psi=\frac{1}{\sqrt{N !}}\left|\begin{array}{cccc}
\psi_{i}(1) & \psi_{j}(1) & \cdots & \psi_{k}(1) \\
\psi_{i}(2) & \psi_{j}(2) & \cdots & \psi_{k}(2) \\
\vdots & \vdots & & \vdots \\
\psi_{i}(N) & \psi_{j}(N) & \cdots & \psi_{k}(N)
\end{array}\right|
$$


onde as $\psi^{\prime} s$ são funções de onda das coordenadas espaciais e do spin de um único elétron, chamadas de spin-orbitais.

O método de Hartree-Fock admite que cada elétron se move sob a ação da carga nuclear, as interações explícitas entre os elétrons são desprezadas, mas é considerado que cada elétron interage com um campo médio causado pelos outros elétrons. $\mathrm{O}$ princípio variacional é usado para se obter os obitais que minimizam a energia, estes orbitais satisfazem à equação de Hartree-Fock [46, 40]

$$
\hat{\boldsymbol{F}} \psi_{i}=\varepsilon_{i} \psi_{i} \quad i=1,2 \ldots, n
$$

onde $\hat{\boldsymbol{F}}$ é o operador de Fock $[46,40]$ e $\varepsilon_{i}$ são as energias dos spin orbitais. O operador de Fock é composto de outros três termos

$$
\hat{\boldsymbol{F}}=\hat{\boldsymbol{H}}_{\text {core }}+\sum_{j}\left[2 \hat{\boldsymbol{J}}_{j}-\hat{\boldsymbol{K}}_{j}\right]
$$

onde $\hat{\boldsymbol{H}}_{\text {core }}$ é o hamiltoniano para 1 elétron que se move sob a ação do núcleo. O termo $\hat{\boldsymbol{J}}_{j}$ representa um potencial médio de coulomb devido à densidade eletrônica dos outros elétrons. Ao último termo $\hat{\boldsymbol{K}}_{j}$ (conhecido como termo de exchange) não é dada interpretação clássica como o termo de Coulomb e tem origem na propriedade de antissimetria da função de onda total do sistema. Tanto $\hat{\boldsymbol{J}}_{j}$ como $\hat{\boldsymbol{K}}_{j}$ dependem do orbital $\psi_{i}$, e assim, $\hat{F}$ em 3.5 também depende de $\psi_{i}$. Devido à dependência que o operador de Fock tem com os próprios orbitais, a equação é resolvida de forma autoconsistente.

Uma aproximação para os orbitais moleculares $\psi_{i}$ consiste em escrevê-los como uma combinação linear de orbitais atômicos ( $L C A O$ - linear combination of atomic orbitals) da forma

$$
\psi_{i}=\sum_{\mu} c_{\mu i} \phi_{\mu}
$$


onde os orbitais $\phi_{\mu}$ são um conjunto de funções conhecidas, e os termos $c_{\mu i}$ 's são coeficientes que devem ser determinados pelo princípio variacional. Roothaan [47] propôs utilizar este tipo de expansão para a função de onda de sistemas moleculares e introduziu um tratamento matricial para se resolver a equação de Hartree-Fock. O método de Hartree-Fock-Roothaan como é conhecido, pode ser implementado de forma bastante eficiente do ponto de vista computacional.

\subsubsection{Funções base}

Entre as formas matemáticas possíveis para as funções $\phi_{\mu}$ na expansão dos orbitais moleculares da equação (3.6) estão as funções de Slater [48] e as funções gaussianas [49]. As funções gaussianas são amplamente usadas devido ao menor custo computacional, embora não tenham a mesma dependência radial das funções do tipo Slater, que representam o comportamento radial correto para orbitais do átomo de hidrogênio. Para obter uma combinação de bom comportamento funcional e de eficiência computacional, são usadas combinações lineares de gaussianas de modo que é possível buscar uma concordância boa entre eficiência e precisão [50]. É permitido uma flexibilidade nas bases, no sentido de que se pode aumentar o número de funções bases na expansão dos orbitais atômicos, porém isto resulta em maiores esforços nos cálculos. Por exemplo, a função de Slater 1s normalizada tem a forma

$$
\phi_{1 s}^{\text {Slater }}(r)=\left(\zeta^{3} / \pi\right)^{1 / 2} e^{-\zeta r}
$$

onde $\zeta$ é o expoente orbital de Slater. A função gaussiana 1s normalizada é dada por

$$
\phi_{1 s}^{\text {gaussiana }}(r)=(2 \alpha / \pi)^{3 / 4} e^{-\alpha r^{2}}
$$

onde $\alpha$ é o expoente orbital gaussiano. Para contornar o problema do comportamento radial inapropriado da função gaussiana em relação à de Slater, usa-se uma 
combinação linear das funções dadas em 3.8 (funções primitivas). A esta combinação se dá o nome de funções gaussianas contraídas escrita abaixo

$$
\phi_{1 s}^{\text {cont }}(r)=\sum_{i} c_{i} \phi_{i}^{\text {gaussiana }}(r)
$$

onde $c_{i}$ é o coeficiente de contração. A escolha da quantidade de funções primitivas, dos parâmetros $c$ e $\alpha$ permite obter uma boa concordância das funções do tipo gaussianas para aproximar a forma funcional das funções tipo Slater. Na figura 3.1 estão representados o comportamento das funções de Slater e as funções contraídas do tipo gaussiana para fitar o comportamento da função de Slater, onde se usam uma, duas e três primitivas com os parâmetros $c$ e $\alpha$ que fornecem o melhor ajuste para a função do tipo Slater [40].

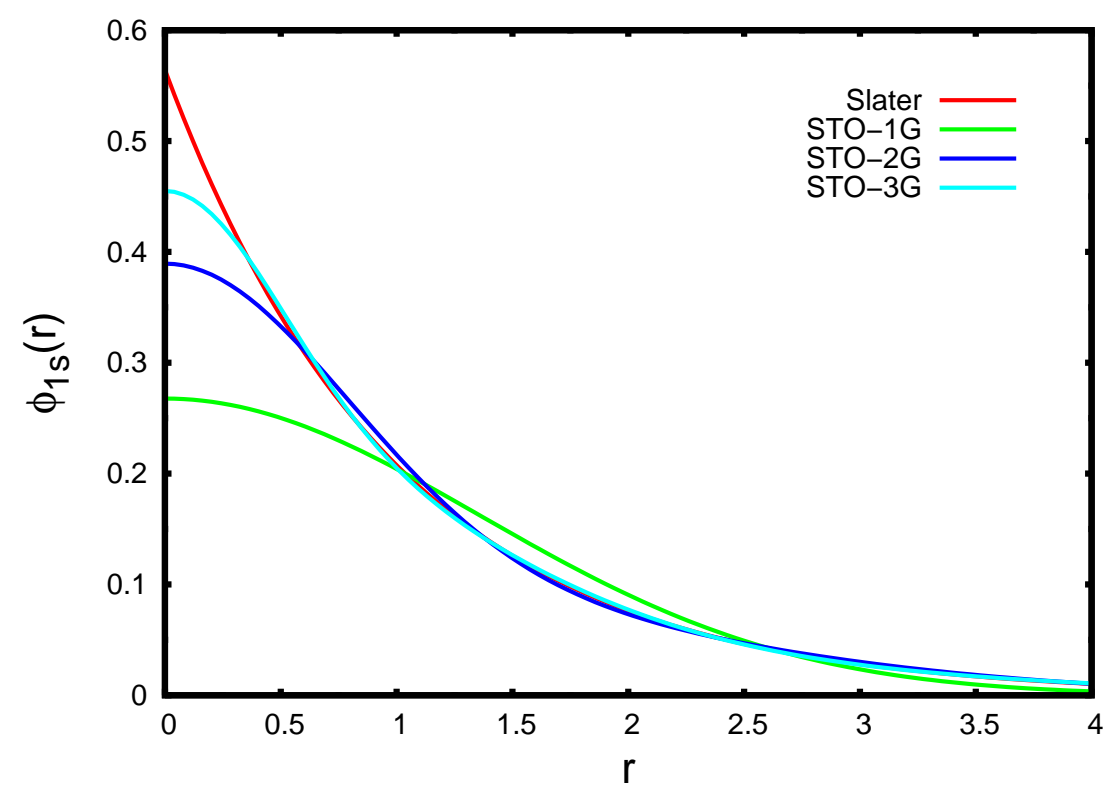

Figura 3.1: Comparação entre os comportamentos funcionais das funções de Slater (STO) e as funções gaussianas contraídas contendo uma primitiva (STO-1G), duas (STO-2G) e três primitivas (STO-3G). As funções são centradas no núcleo atômico e r é a distância elétron-núcleo.

Além do aumento da quantidade de funções que formam a base, podem ser 
incluídas funções de número quântico do momento angular mais elevado que o das funções $s(l=0)$ e $p(l=1)$, e estes são os casos das funções de polarização. Por exemplo, adicionando funções $d(l=2)$ aos átomos de carbono, ou funções $p$ aos átomos de hidrogênio, essas funções de polarização dão flexibilidade quanto à forma dos orbitais $[42,51]$. As funções difusas tentam descrever o comportamento de elétrons fracamente ligados e afastados do núcleo.

\subsection{Métodos pós-Hartree-Fock}

O tratamento que se dá aos sistemas multieletrônicos através do método de Hartre-Fock é incompleto no que diz respeito à correlação eletrônica. A energia de

correlação eletrônica é definida como $E_{c o r r}=E_{\text {exata }}-E_{H F}$, onde $E_{c o r r}$ é a energia de correlação, $E_{\text {exata }}$ é a energia exata não relativista e $E_{H F}$ é a energia obtida com cálculo Hartree-Fock. Os métodos que procuram corrigir esta deficiência são chamados de pós-Hartree-Fock. Entre eles estão os métodos de interação de configurações (CI - Configuration Interaction) e teoria de perturbação de muitos corpos (MBPT - Many Body Perturbation Theory).

\subsubsection{Interação de configurações}

A aproximação de Hartree-Fock considera apenas um único determinante para descrever o sistema de vários elétrons e esta é uma das fontes de erro. No método interação de configurações a função de onda do sistema é escrita como uma combinação linear de determinantes de Slater

$$
\Phi=C_{0} \Psi_{0}+C_{S} \Psi_{S}+C_{D} \Psi_{D}+\ldots
$$

onde o determinante $\Psi_{0}$ é tomado como referência, sendo obtido num cálculo HartreeFock e considerado como uma boa aproximação para $\Phi$. Os coeficientes $C_{0}, C_{S}, \ldots$ 
são determinados variacionalmente e os índices $S, D, \ldots$ significam que existem substituições dos elétrons de orbitais ocupados para orbitais não ocupados, ou seja, determinantes com substituições simples $\Psi_{S}$, com substituições duplas $\Psi_{D}$, e assim por diante. Cálculos que consideram todas as possíveis configurações (conhecidos como Full CI) estão restritos a poucos sistemas, portanto esta série deve ser truncada num certo nível de substituições.

Ao considerar substituições simples (CIS), o método CI não melhora a energia obtida no cálculo Hartree-Fock para estado fundamental. Isto se deve ao fato de que nos cálculos CI os elementos de matriz entre $\Psi_{0}$ (função de onda HF) e as funções com substituições simples são nulos, o que é conhecido como teorema de Brillouin $\left(\left\langle\Psi_{0}|H| \Psi_{S}\right\rangle=0\right)[34]$. As substiuições duplas influenciam diretamente nos cálculos que envolvem correlação eletrônica e os cálculos que utilizam substituições simples e duplas (CISD) são bastante utilizados. As substituições simples são incluídas pois interagem com as duplas, portanto ocorre uma interação indireta entre $\Psi_{0}$ e $\Psi_{S}$. A inclusão de substituições duplas permite, por exemplo, obter uma expressão para a energia de correlação eletrônica [34, 40]

$$
E_{\text {corr }}=\sum_{\substack{a<b \\ r<s}} C_{a b}^{r s}\left\langle\Psi_{0}|H| \Psi_{a b}^{r s}\right\rangle
$$

que não pode ser obtida num cálculo de único determinante.

\subsubsection{Teoria de perturbação de Møller Plesset}

A teoria de perturbação propõe que se escreva o hamiltoniano do sistema como uma soma de dois termos

$$
\hat{\boldsymbol{H}}=\hat{\boldsymbol{H}}_{0}+\lambda \hat{\boldsymbol{V}}
$$

onde $\hat{\boldsymbol{H}}_{0}$ é um operador com autovalores (energias) e autofunções (funções de onda)

conhecidas e $\hat{\boldsymbol{V}}$ é um operador que representa uma perturbação em $\hat{\boldsymbol{H}}_{0}$, onde estão 
inclusos operadores de uma e duas partículas. A teoria de perturbação apresenta um procedimento que melhora as autofunções e autovalores do hamiltoniano não perturbado, fazendo com que estas se aproximem das soluções de $\hat{\boldsymbol{H}}$. O parâmetro $\lambda$ introduz o ordenamento das correções, pois assumindo que a perturbação seja pequena, os autovalores e autofunções são escritos como uma expansão de Taylor em potências de $\lambda$. A teoria de perturbação desenvolvida desta forma é conhecida como teoria de perturbação de Rayleigh-Schrödinger [34, 41]. Buscando obter correções para a energia em sistemas de vários elétrons, Møller e Plesset [52] propuseram escrever o hamiltoniano não perturbado como a soma de operadores de Fock [34]. A função de onda de referência (Hartree-Fock) é autofunção de $\hat{\boldsymbol{H}}_{0}$ e pode-se mostrar $[40,34]$ que a perturbação até primeira ordem fornece a energia da solução de Hartree-Fock. Parte da energia de correlação eletrônica é obtida a partir da correção de segunda ordem em teoria de perturbação, e que envolvem o cálculo de elementos de matriz entre os estado de referência (Hartree-Fock) e os estados com substituições simples, duplas e superiores. Para a correção em segunda ordem, existe a necessidade de incluir apenas as substituições duplas, como pode ser visto pela expressão da energia de segunda ordem [34]

$$
E^{(2)}=\sum_{\substack{a<b \\ r<s}} \frac{\left|\left\langle\Psi_{0}|\hat{\boldsymbol{V}}| \Psi_{a b}^{r s}\right\rangle\right|}{E_{0}-E_{r s}}
$$

conhecida como como MP2. Seguindo através das correções para ordens superiores, se obtém que em correções de terceira ordem há a presença de substituições duplas e a correção de quarta ordem apresenta além de substituições duplas, termos onde estão presentes determinantes com substituições simples, duplas, triplas e quádruplas. 


\subsubsection{Teoria do funcional da densidade}

A teoria do funcional da densidade (DFT-Density Functional Theory) é outro método bastante usado em cálculos de química teórica. A formulação da DFT está baseada nos teoremas de Hohenberg e Kohn [53]. O teorema afirma que o potencial externo $v(r)$ (aquele devido aos núcleos em uma molécula) é determinado pela densidade eletrônica $n(r)$. A integração de $n(r)$ fornece o número de elétrons $\mathrm{N}$, que junto com a própria densidade, determinam o hamiltoniano $\mathrm{H}(H=T+U+V)$ e todas a propriedades determinadas por ele, onde $\mathrm{T}$ é a energia cinética do elétrons, $\mathrm{U}$ é a energia de interação mútua entre eles e V o potencial externo. A função de onda também é um funcional da densidade, e o valor esperado de um observável como a energia, por exemplo, é um funcional da densidade. Um segundo teorema mostra que a energia obedece a um princípio variacional, onde para um dado potencial $v(r)$, é procurada a $n(r)$ que minimiza o funcional energia $E[n(r)][54]$

$$
E[n(r)] \equiv \int v(r) n(\boldsymbol{r}) d r+F[n(r)]
$$

onde

$$
F[n(r)] \equiv\langle\Psi[n(r)]|(T+V)| \Psi[n(r)]\rangle
$$

é um funcional de $n(r)$ e está sujeito a aproximações como a de Thomas-Fermi $[54,55]$.

A forma de implementação mais usada hoje em DFT é a sugerida por Kohn e Sham [56]. A aproximação de Kohn-Sham (KS) propõe escrever o funcional $F[n(r)]$ como

$$
F[n(r)]=T_{n i}[n(r)]+\frac{1}{2} \int \frac{n(r) n\left(r^{\prime}\right)}{\left|r-r^{\prime}\right|} d r d r^{\prime}+E_{x c}[n(r)]
$$

onde o funcional energia cinética é separado em $T_{n i}[n(r)]$, a energia cinética de um sistema de partículas não interagentes e $T_{c}[n(r)]$, relacionado à correlação. O segundo termo na expressão 3.16 é a expressão clássica para a energia de interação. O 
termo $E_{x c}[n(r)]$ é chamado de energia de troca-correlação (exchange-correlation) e é decomposto em duas partes, $E_{x c}=E_{x}+E_{c}$ (troca e correlação), onde o termo $E_{c}$, portanto, contém o termo $T_{c}$. O termo ou funcional de troca-correlação é desconhecido, e portanto, são feitas aproximações para ele [55, 51]. Os chamados funcionais híbridos misturam uma fração da energia de troca de Hartree-Fock com a energia de troca da DFT, e podem conter parâmetros ajustáveis. A terminologia usada para denominar os funcionais geralmente liga o nome para o funcional de troca ao funcional de correlação. Por exemplo, o funcional híbrido B3P86, contém o funcional de troca de Becke de três parâmetros [57] e o funcional de correlação de Perdew [58]. Assim como o funcional B3LYP, composto pelo funcional de troca de Becke e o funcional de correlação de Lee, Yang e Parr [59].

Na aproximação de KS são introduzidos os orbitais de uma partícula $\phi_{i}^{K S}$ que satisfazem a equação de autovalores

$$
\left(-\frac{1}{2} \nabla^{2}+v(r)+\int \frac{n\left(r^{\prime}\right)}{\left|r-r^{\prime}\right|} d r^{\prime}+v_{x c}(r)-\epsilon_{i}\right) \phi_{i}^{K S}(r)=0
$$

que é resolvida de maneira autoconsistente. A cada ciclo o potencial de trocacorrelação

$$
v_{x c}(r)=\frac{\delta E_{x c}[n(r)]}{\delta n(r)}
$$

é calculado, com a aproximação definida para $E_{x c}[n(r)]$. Os orbitais solução da equação 3.17 fornecem a densidade eletrônica que é obtida de

$$
n(r)=\sum_{i}^{N}\left|\phi_{i}^{K S}(r)\right|^{2}
$$

e que é novamente usada no ciclo autoconsistente.

A teoria foi desenvolvida também para problemas dependentes do tempo, conhecida como TDDFT (Time Dependent Functional Theory). Num teorema análogo ao 
de Hohenberg e Kohn, Runge e Gross demonstram a correspondência entre a densidade eletrônica $\rho(r, t)$ dependente do tempo e o potencial externo $v(r, t)[60,61]$. Da mesma forma que na teoria independente do tempo, os orbitais de uma partícula que definem a densidade $n(r, t)=\sum_{i}^{N}\left|\phi_{i}^{K S}(r, t)\right|^{2}$ são soluções de uma equação dependente o tempo análoga à equação de Kohn-Sham 3.17. A implementação utilizada aqui é a da teoria da resposta linear [62], onde o potencial externo dependente do tempo é tratado como uma fraca perturbação no estado fundamental. Detalhes sobre as aproximações e técnicas usadas são expostas em [62]. 


\section{Capítulo 4}

\section{Método Sequencial QM/MM}

O método sequencial $Q M / M M$ é um método híbrido utilizado para estudar os efeitos de solvente em sistemas atômicos e moleculares. Uma simulação clássica Monte Carlo (MC) ou de dinâmica molecular é realizada numa primeira etapa. Em seguida, uma análise estatística desta simulação permite determinar um intervalo entre as configurações geradas na simulação, e deste intervalo é possível retirar configurações estatisticamente descorrelacionadas entre si. Numa segunda etapa, são realizados cálculos por métodos de mecânica quântica sobre estas configurações e as propriedades de interesse são obtidas como médias simples sobre o número de configurações. Maiores detalhes e aplicações a vários problemas podem ser encontrados em [63, 64]. Nesta tese, as simulações Monte Carlo foram realizadas utilizando o programa DICE [65]. Além do DICE, dois outros programas (Correlation e Order) auxiliam as análises após as simulações, como: cálculo do intervalo de correlação e análise das camadas de solvatação e ligações de hidrogênio. 


\subsection{Análise estatística das configurações}

Cada configuração é um conjunto das coordenadas de todos os átomos e moléculas presentes na simulação MC. Um número muito grande de configurações é gerado no final de cada simulação, e a análise estatística permite encontrar o intervalo satisfatório para que as configurações sejam consideradas descorrelacionadas entre si. Com este intervalo é possível reduzir o número de configurações que irão fornecer resultados relevantes para as propriedades que estamos interessados. No final, o que obtemos é uma média simples e convergida de tais propriedades, como se pode ver no esquema da figura 4.1.

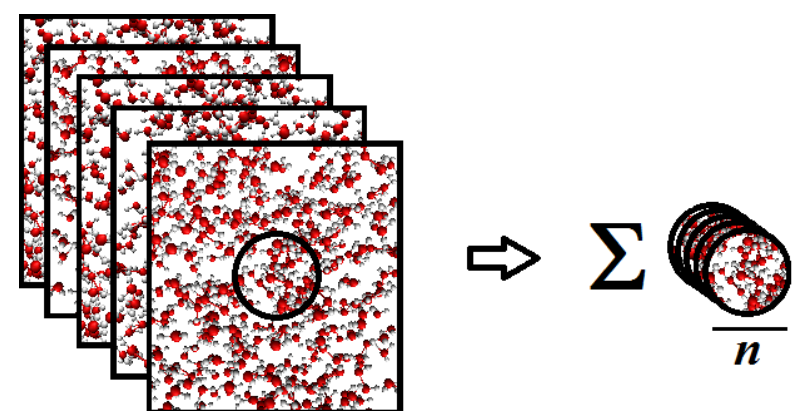

Figura 4.1: Representação esquemática das configurações descorrelacionadas e a região delimitada pelo círculo que é submetida aos cálculos de mecânica quântica. Ao final temos uma média simples convergida da propriedade que estamos interessados. Figura retirada de [66].

O valor médio $\langle f\rangle$ de uma propriedade obtida na simulação é dada por

$$
\langle f\rangle_{L}=\frac{1}{L} \sum_{i=1}^{L} f_{i}
$$

onde $L$ é o número de configurações, definindo o tamanho da simulação. Se esta propriedade for a energia, por exemplo, seu valor médio e a variância da média serão 
dados por

$$
\langle U\rangle_{L}=\frac{1}{L} \sum_{i=1}^{L} U_{i}
$$

$\mathrm{e}$

$$
\left\langle\delta U^{2}\right\rangle_{L}=\frac{1}{L} \sum_{i=1}^{L}\left(U_{i}-\langle U\rangle_{L}\right)^{2}=\left\langle U^{2}\right\rangle_{L}-\langle U\rangle_{L}^{2}
$$

A função de autocorrelação da energia $C(k)$ é definida pela expressão [39, 63, 64]

$$
C(k)=\frac{\left\langle\delta U_{i} \delta U_{i+k}\right\rangle}{\left\langle\delta U^{2}\right\rangle}
$$

onde $U_{i}$ é a energia da i-ésima configuração e $U_{i+k}$ é a energia da configuração que foi gerada após $k$ passos MC. O intervalo de correlação $\tau$ é definido pela integral da função de autocorrelação

$$
\tau=\int_{0}^{\infty} C(k) d k
$$

Para processos markovianos, $C(k)$ apresenta um decaimento exponencial do tipo

$$
C(k)=\sum_{i} c_{i} e^{-\frac{k}{\tau_{i}}}
$$

Em nossas simulações de sistemas líquidos, observamos que um melhor ajuste é obtido por uma exponencial dupla

$$
C(k)=c_{1} e^{-\frac{k}{\tau_{1}}}+c_{2} e^{-\frac{k}{\tau_{2}}}
$$

A integral da equação 4.5 com $C(k)$ dada pela expressão 4.5 fornece $\tau=c_{1} \tau_{1}+c_{2} \tau_{2}$ e em geral se obtem configurações descorrelacionadas separadas por um intervalo de $k \approx 2 \tau$. A figura 4.2 exemplifica este ajuste. O intervalo considerado satisfatório fornece configurações que apresentem em torno de $13 \%$ de correlação entre si. 


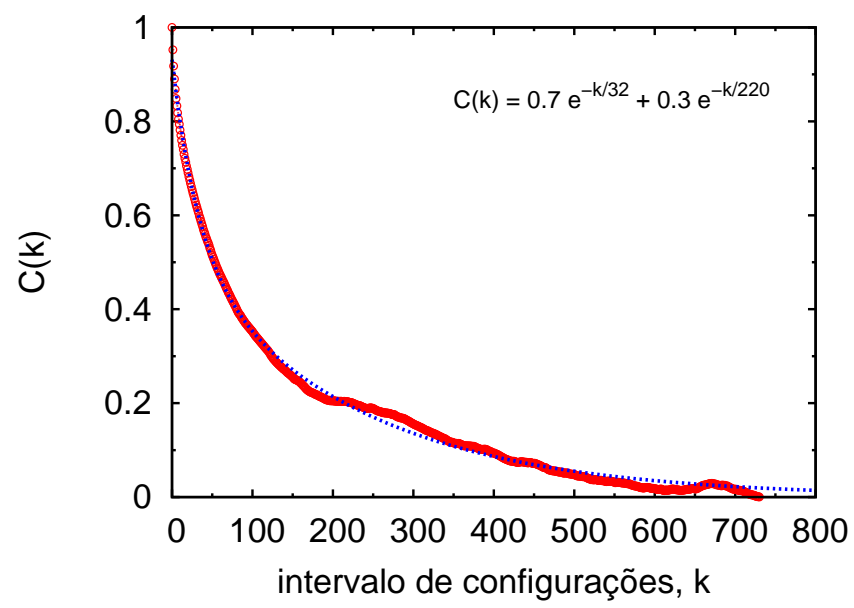

Figura 4.2: Função de autocorrelação da energia e o ajuste com a dupla exponencial para uma simulação de argônio líquido. Na região interna ao gráfico é mostrada a equação 4.7 com os parâmetros obtidos pelo ajuste da curva.

\subsection{Análise estrutural}

A análise estrutural é feita com o auxílio da função de distribuição radial de pares $g(r)$, definida no capítulo 2. Neste procedimento a estrutura do solvente ao redor do soluto é definida, as camadas de solvatação são interpretadas e possíveis ligações de hidrogênio entre soluto e solvente podem ser observadas pela inspeção dos primeiros picos na curva da $g(r)$. A escolha da quantidade de moléculas explícitas a serem incluídas nos cálculos quânticos é geralmente baseada número de coordenação $N(r)$. Ao se fazer a análise estrutural, é comum escolher diferentes regiões da molécula, indexando certos átomos no soluto e assim obter a distribuição do solvente ao redor de um átomo específico. 


\section{Capítulo 5}

\section{Polarizabilidade do Argônio Líquido}

A polarizabilidade estática de um sistema atômico ou molecular define a capacidade que este sistema tem em se tornar polarizado. Quando estão sob a ação de um campo elétrico, os átomos e moléculas apresentam uma resposta a este campo, produzindo uma deformação da sua densidade eletrônica. O momento de dipolo que é induzido devido à presença do campo eletrostático homogêneo $\boldsymbol{F}$ pode ser representado pela expansão [43]

$$
\boldsymbol{\mu}=\boldsymbol{\mu}_{\mathbf{0}}+\boldsymbol{\alpha} \boldsymbol{F}+\frac{1}{2} \boldsymbol{\beta} \boldsymbol{F}^{2}+\frac{1}{6} \boldsymbol{\gamma} \boldsymbol{F}^{3}+\cdots
$$

Para campos fracos, os termos de ordem superior não são considerados e temos a seguinte expressão [34]

$$
\mu=\mu_{0}+\alpha F
$$

onde $\boldsymbol{\mu}_{\mathbf{0}}$ é o momento de dipolo permanente, se houver. O termo $\alpha$ é a polarizabilidade estática do sistema. Os termos de ordem superior são importantes em regimes de campos mais intensos e são chamados de hiperpolarizabilidades, estando 
relacionados a fenômenos de ótica não linear. Outras propriedades físicas relacionadas com a polarizabilidade são: o índice de refração e a constante dielétrica dos materiais. Para campos aplicados que sejam dependentes da frequência $\boldsymbol{F}=\boldsymbol{F}(\omega)$, a polarizabilidade (neste caso, polarizabilidade dinâmica) é importante no estudo da espectroscopia Raman [34, 67] de sistemas moleculares. A atividade no espectro Raman vibracional está relacionada com variações da polarizabilidade, causada pelas vibrações dos núcleos que compõem as moléculas. Para situações onde $\omega=0$, temos a polarizabilidade estática, que é o caso estudado neste capítulo.

Existem trabalhos nos quais são discutidos os efeitos da perturbação do meio líquido sobre a polarizabilidade de sistemas atômicos e moleculares. É sugerido que ocorra um decréscimo desta propriedade na fase líquida em relacão à fase gasosa $[68,69]$ devido a um efeito de confinamento imposto pelo meio solvente. A polarizabilidade do argônio líquido foi estudada em outro trabalho [18, 19] e o resultado aponta para um aumento na polarizabilidade do sistema em fase líquida. Neste caso é feita a comparação às situações extremas entre líquido e gás.

Este capítulo mostra um estudo da polarizabilidade do argônio calculada para a situação de estado líquido onde queremos verificar como se comporta a polarizabilidade estática deste átomo quando se varia a pressão sobre o sistema. Se o aumento de pressão causar maior efeito de confinamento no sistema atômico, isto pode se refletir na polarizabilidade do átomo. Utilizamos aqui uma aproximação para se obter a polarizabilidade do átomo de argônio. Nesta aproximação assumimos a separabilidade das contribuições do soluto e do solvente, onde aqui o soluto é o átomo de argônio e o solvente também é formado pelos átomos de argônio numa estrutura de supermolécula, vinda das simulações MC. Este procedimento foi utilizado em trabalhos anteriores para o cálculo de polarizabilidade de átomos, íons como o $\mathrm{F}^{-}$ [70], pequenas moléculas [68, 71, 72], onde se mostraram bons resultados.

Utilizamos o método sequencial QM/MM onde na etapa de simulação clássica 
Monte Carlo geramos o conjunto de configurações do líquido. Terminada a etapa de simulação, as configurações estatisticamente descorrelacionadas são separadas e submetidas aos cálculos de mecânica quântica para se obter a polarizabilidade como valores estatisticamente convergidos.

\subsection{Detalhes da simulação e cálculos}

As simulações foram realizadas no ensemble NPT com o sistema composto de 500 átomos de argônio em uma caixa cúbica. Para a pressão foram escolhidos valores que variam entre $1.8 \mathrm{~atm}$ até $32 \mathrm{~atm}$. De acordo com a figura 5.1, vemos que este intervalo ainda corresponde ao estado líquido à temperatura de $91.8 \mathrm{~K}$. Por isso tais valores de pressão garantem um sistema em fase líquida para os cálculos de polarizabilidade. Os parâmetros utilizados para o potêncial de Lennard-Jones foram $\epsilon=0.2378 \mathrm{kcal} / \mathrm{mol}$ e $\sigma=3.41 \AA[73]$. A figura abaixo mostra o diagrama de fases do argônio, onde se vê as condições termodinâmicas em que ocorrem as diferentes fases do sistema.

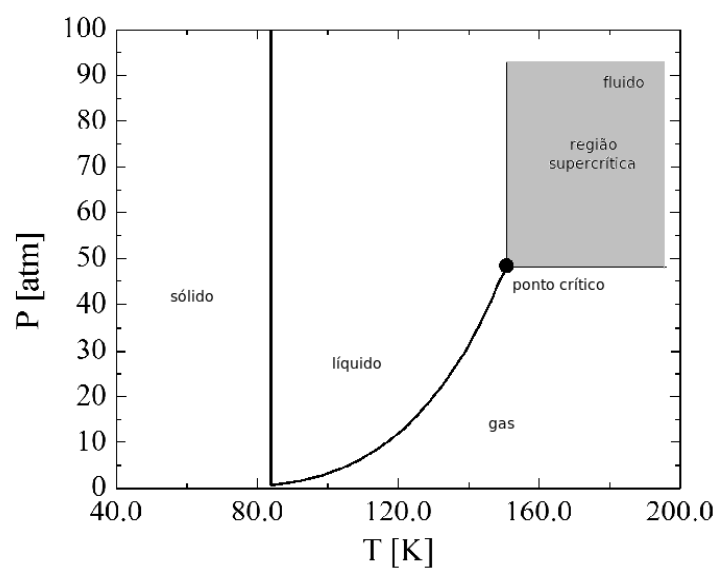

Figura 5.1: Diagrama de fases do argônio. O ponto crítico corresponde a $T_{c}=$ $150.7 \mathrm{~K}$ e $P_{c}=48.6 \mathrm{~atm}$ [74]. 
Um estágio de termalização é realizado na simulação MC para garantir que as propriedades termodinâmicas na simulação sejam obtidas com o sistema em equilíbrio. Para o estágio de termalização foi realizada uma simulação de $2.5 \times 10^{6}$ passos MC. Em seguida, para a simulação no equilíbrio foram realizados $12.5 \times 10^{6}$ passos MC. Um passo MC é definido aqui quando todos os $N$ átomos são visitados e submetidos às regras de aceitação ou rejeição dos movimentos, como descrito no capítulo 2. No estágio de equilíbrio são geradas as configurações do líquido, assim como a função de distribuição radial de pares.

Os valores da densidade calculada durante as simulações são mostrados na tabela 5.1. O valor obtido para a condição de $91.8 \mathrm{~K}$ e $1.8 \mathrm{~atm}$ é de $1.362 \pm 0.015 \mathrm{~g} / \mathrm{cm}^{3}$, enquanto que o valor experimental é de $1.365 \mathrm{~g} / \mathrm{cm}^{3}$ [75].

Tabela 5.1: Valores das densidades obtidas nas simulações MC para cada valor de pressão considerado. Todas realizadas a uma temperatura de $91.8 \mathrm{~K}$.

\begin{tabular}{cc}
\hline \hline Pressão $(\mathrm{atm})$ & Densidade $\left(\mathrm{g} / \mathrm{cm}^{3}\right)$ \\
\hline 17 & $1.368 \pm 0.015$ \\
22 & $1.368 \pm 0.015$ \\
27 & $1.370 \pm 0.015$ \\
32 & $1.372 \pm 0.014$ \\
\hline \hline
\end{tabular}

O intervalo entre as configurações usadas para os cálculos de polarizabilidade é obtido através da função de autocorrelação da energia e as configurações apresentam menos de 10\% de correlação entre si. Da função de distribuição radial de pares (figura 5.2), obtém-se por integração que a primeira camada de solvatação é composta de 14 átomos de argônio. Para todas as simulações a primeira camada se inicia aproximadamente em $3.20 \AA$, com um máximo em $3.75 \AA$, terminando em $5.35 \AA$. A integração sob o primeiro pico, o qual fornece o número médio de átomos na primeira camada também não sofre variações no intervalo de pressões que consideramos neste estudo. 


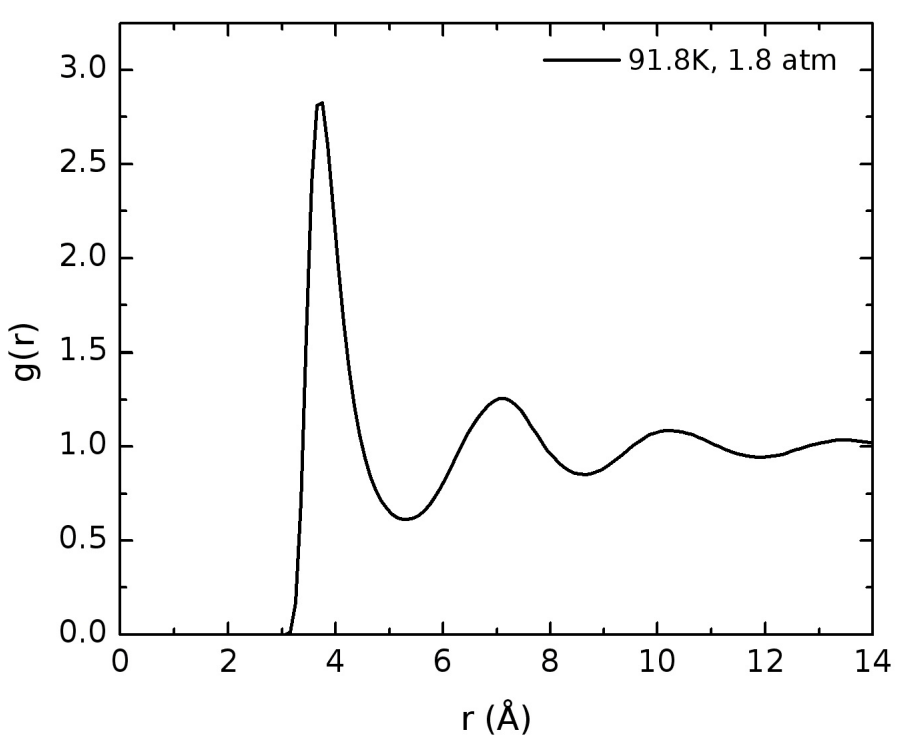

Figura 5.2: Função $g(r)$ do argônio líquido a $T=91.8 \mathrm{~K}, \mathrm{P}=1.8$ atm, onde o valor médio obtido para a densidade foi de $1.362 \mathrm{~g} / \mathrm{cm}^{3}$.

\subsection{Cálculo da polarizabilidade}

O cálculo da polarizabilidade do átomo isolado foi feito para a referência e comparações com os valores em líquido, assim como sob variações da pressão. O nível de cálculo utilizado foi DFT com o funcional B3P86 [57, 58] e base aug-cc- $p V D Z[76]$. O valor para átomo isolado obtido por nós foi de $9.98 a_{0}^{3}$. Os valores experimentais estão em torno de $11.070 \pm 0.05 a_{0}^{3}$ [77] e $11.078 \pm 0.010 a_{0}^{3}$ [78]. A polarizabilidade é dada em unidades atômicas $\left(a_{0}^{3}\right)$, onde $a_{0}$ é o raio de Bohr. Para converter em $\AA^{3}$ usa-se: $1 a_{0}^{3}=(4 / 27) \AA^{3}$.

Passamos então para o cálculo da polarizabilidade em fase líquida. Utilizamos no cálculo em fase líquida as configurações vindas das simulações MC. A polarizabilidade de cada configuração será o valor médio vindo das três componentes diagonais 
do tensor polarizabilidade, isto é, $\langle\alpha\rangle=\left(\alpha_{x x}+\alpha_{y y}+\alpha_{z z}\right) / 3$.

A aproximação que nos referimos no início do capítulo consiste em tomar cada configuração em duas situações. Primeiramente o cálculo é realizado sobre as configurações contendo os 14 átomos de Ar que compõem o cluster. Em seguida as mesmas configurações são novamente submetidas aos cálculos mas com o átomo central (soluto) ausente. A polarizabilidade atômica do argônio é obtida como a diferença entre as duas situações. O resultado final é expresso pela equação 5.3

$$
\alpha(A r)=\alpha(A r+13 A r)-\alpha(0+13 A r)
$$

O primeiro termo do lado direito é a polarizabilidade do cluster composto pelos 14 átomos de argônio. O segundo é a polarizabilidade do cluster sem o átomo central. Da diferença entre estes termos obtemos a polarizabilidade atômica do argônio. Esta equação se aplica a cada uma das configurações e o valor da polarizabilidade do argônio líquido é obtida como a média convergida sobre estas configurações. Os resultados foram obtidos no mesmo nível em que foi realizado o cálculo para o átomo isolado e foi usado o programa Gaussian03 [79] para os cálculos.

A tabela 5.2 apresenta os valores da polarizabilidade média. São valores estatisticamente convergidos e são uma média sobre as configurações descorrelacionadas. Todos os valores são referentes à temperatura de $91.8 K$ na qual as simulações MC foram realizadas. Para a pressão de $1.8 \mathrm{~atm}$ o valor obtido foi de $11.529 \pm 0.092 \mathrm{a}_{0}^{3}$, sendo que esta é a situação de menor pressão que consideramos no sistema líquido. A figura 5.3 mostra a convergência estatística da polarizabilidade calculada para o caso onde a pressão considerada é de $22 \mathrm{~atm}$.

A partir dos resultados da tabela 5.2, vemos que a polarizabilidade em fase condensada apresenta um aumento em relação ao cálculo para átomo isolado. A comparação com valores experimentais pode ser feita considerando o valor da constante 
Tabela 5.2: Resultados para polarizabilidade $\alpha(A r)$ do argônio líquido sob diferentes valores de pressão. Os valores são dados com o desvio padrão.

\begin{tabular}{cc}
\hline \hline Pressão $(\mathrm{atm})$ & Polarizabilidade $\left(a_{0}^{3}\right)$ \\
\hline 17 & $11.544 \pm 0.100$ \\
22 & $11.544 \pm 0.074$ \\
27 & $11.548 \pm 0.087$ \\
32 & $11.543 \pm 0.112$ \\
\hline \hline
\end{tabular}

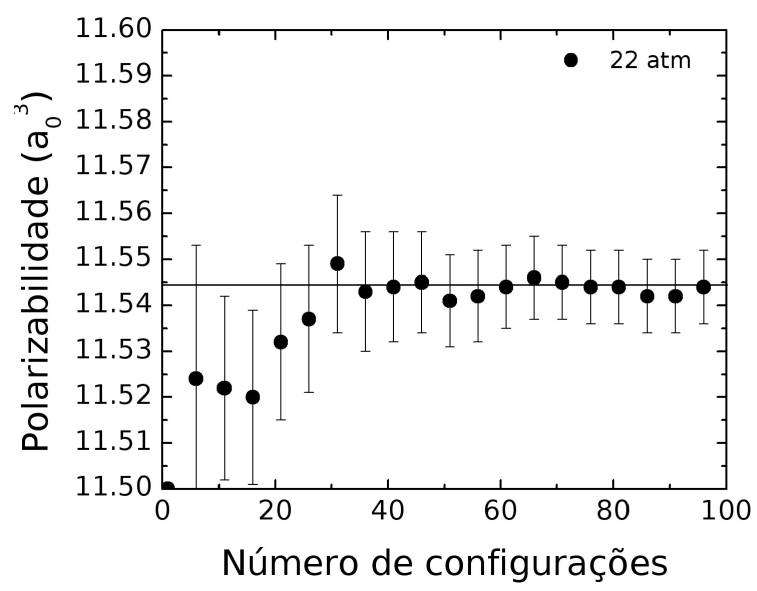

Figura 5.3: Convergência estatística da polarizabilidade do argônio líquido. As condiçôes termodinâmicas são $91.8 \mathrm{~K}$ e $22 \mathrm{~atm}$. A barra de erros correspondem ao erro estatístico.

dielétrica $\varepsilon$ para o argônio líquido que é obtida pela relação de Clausius-Mosotti [80]

$$
\frac{\varepsilon-1}{\varepsilon+2}=\frac{4 \pi \alpha}{3} \rho \frac{N_{A}}{M}
$$

onde $\alpha$ é a polarizabilidade calculada, $\rho$ é a densidade, $M$ e $N_{A}$ são a massa molar e o número de Avogadro, respectivamente. O valor experimental para a constante dielétrica obtida para argônio a $87.4 \mathrm{~K}$ e $1.0 \mathrm{~atm}$ é de 1.53 [77]. Sob a condição de $91.8 \mathrm{~K}$ e $1.8 \mathrm{~atm}$ considerada aqui e em [19] a equação de Clausius-Mosotti fornece a constante dielétrica de 1.52 , em excelente acordo com o resultado experimental. 
Dos resultados da tabela 5.2 observamos que a variação da polarizabilidade neste intervalo de pressão é bem pequena, inferior ao desvio padrão. Conferindo os valores de densidade na tabela 5.1, verificamos que ela varia pouco com o aumento de pressão. Se admitirmos que a polarizabilidade apresente dependência com a densidade do líquido, podemos dizer que sua quase inexistente variação esteja associada com a pequena variação da densidade do líquido.

\subsection{Polarizabilidade em torno do ponto crítico e condição supercrítica}

Analisamos também a polarizabilidade do argônio em torno do ponto crítico e na região supercrítica. As condições termodinâmicas usadas para o argônio no ponto crítico são $T_{c}=150.7 \mathrm{~K}, \rho_{c}=0.53 \mathrm{~g} / \mathrm{cm}^{3}$ e $P_{c}=48.6 \mathrm{~atm}$ [74]. Nestas condições a simulação foi feita no ensemble NVT, onde mantivemos a densidade do sistema constante. Simulações em condições supercríticas também foram realizadas e esta região é mostrada na figura 5.1 na área sombreada.

As simulações foram realizadas a uma temperatura de $190 \mathrm{~K}$ e foram escolhidos dois valores para a densidade. Estes valores estão na vizinhança do valor crítico, um acima $\left(\rho=0.73 \mathrm{~g} / \mathrm{cm}^{3}\right)$ e outro abaixo $\left(\rho=0.33 \mathrm{~g} / \mathrm{cm}^{3}\right)$. A figura 5.4 mostra a função de distribuição radial de pares entre os átomos de argônio. São mostradas as curvas para o líquido nos dois casos extremos de pressão considerados aqui, a mais baixa e a mais alta (1.8 atm e $32 \mathrm{~atm})$, assim como a $g(r)$ para a condição termodinâmica do ponto crítico e os casos de fluido supercrítico.

O cálculo da polarizabilidade foi realizado com a mesma estrutura formada por 14 átomos, seguindo também a mesma forma de separar o átomo central dos vizinhos, tomando a diferença para obter a polarizabilidade para o átomo. Na tabela 5.3 são apresentados os valores da polarizabilidade nestas condições. O valor calculado para 


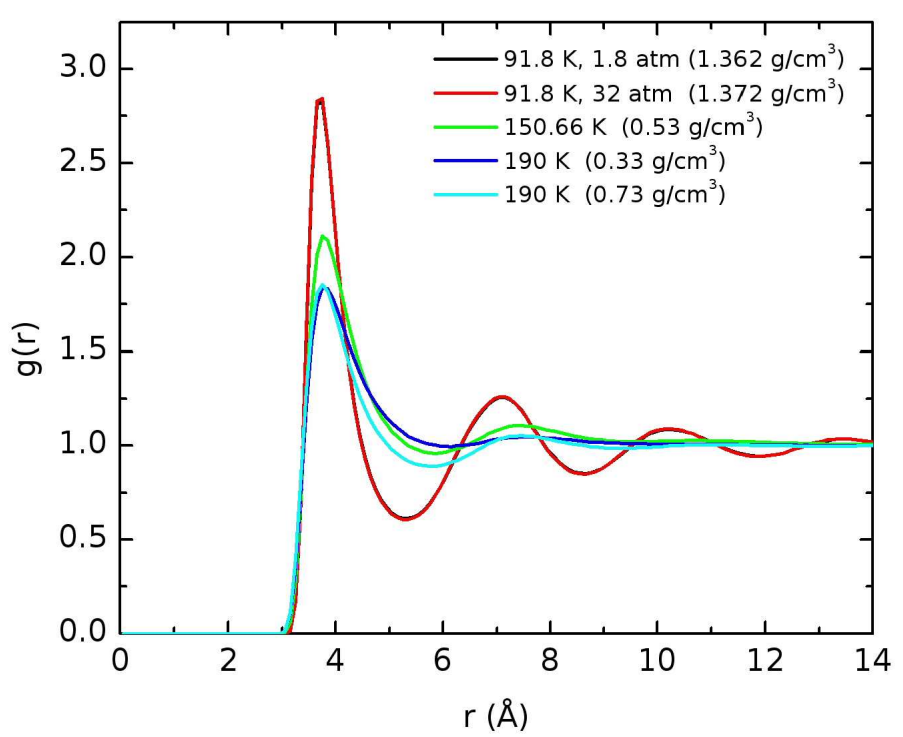

Figura 5.4: Função $g(r)$ para diferentes condições termodinâmicas, incluindo os estados supercríticos.

a polarizabilidade em condição crítica e supercrítica apresentou um decréscimo em relação aos casos anteriores. Para a mesma temperatura, a polarizabilidade mostrou variação com a mudança na densidade do fluido. Utilizando a equação de ClaussiusMosotti, o valor para a constante dielétrica do argônio no ponto crítico pode ser determinada. $\mathrm{O}$ valor que obtemos é de $\varepsilon=1.173 \pm 0.005$, em muito bom acordo com o valor experimental de 1.179 [81].

Tabela 5.3: Valores calculados para a polarizabilidade do argônio em condição crítica e supercrítica.

\begin{tabular}{ccc}
\hline \hline$T(K)$ & $\rho_{c}\left(\mathrm{~g} / \mathrm{cm}^{3}\right)$ & $\alpha\left(a_{0}^{3}\right)$ \\
\hline 150.66 & 0.53 & $10.878 \pm 0.025$ \\
190 & 0.33 & $10.562 \pm 0.023$ \\
190 & 0.73 & $11.012 \pm 0.022$ \\
\hline \hline
\end{tabular}


Podemos reunir algumas conclusões neste capítulo. A polarizabilidade calculada em fase líquida apresentou um aumento em relação à fase gasosa. Porém, os valores da tabela 5.2 mostram que existe uma fraca dependência da polarizabilidade com a pressão imposta na simulação do líquido. Na figura 5.4 pode ser observado que a estrutura do líquido, especialmente nos casos onde a pressão aumenta de $1.8 \mathrm{~atm}$ para $32 \mathrm{~atm}$, não apresenta diferenças. Concluímos então que neste intervalo de variação de pressão aqui considerado, um efeito de confinamento pode não estar ocorrendo com o aumento da pressão.

Na região do ponto crítico, o valor calculado para a polarizabilidade apresentou uma diminuição em relação ao estado líquido, como vemos na tabela 5.3. Para as condições termodinâmicas correspondentes ao estado supercrítico, vemos uma dependência da polarizabilidade com a densidade, como acontece no caso em que a temperatura é de 190 K. Nas condições de fluido supercrítico, a polarizabilidade se mostrou mais sensível à densidade. Este estudo permitiu então a determinação da constante dielétrica do argônio no ponto crítico. 


\section{Capítulo 6}

\section{Espectro Eletrônico do Átomo de Xenônio em Argônio}

Neste capítulo apresentamos os resultados do cálculo de espectro eletrônico de absorção do átomo de xenônio imerso em um meio formado por átomos de argônio (chamaremos este sistema atômico de $X e / A r$ ). Este é um sistema bastante particular e que oferece grandes desafios para se estudar os efeitos da perturbação do meio nas propriedades eletrônicas. Uma abordagem por metodologias de solvente contínuo parece não ser boa alternativa para este caso, pois temos como soluto um átomo inerte, ou seja, não existem momentos de dipolo e momentos eletrostáticos de ordem superior. Além disso, o solvente também é constituído de átomos, então temos um sistema formado por soluto apolar em meio apolar. Além disso, nos modelos de solvente contínuo não é possível explorar diferentes condições termodinâmicas de temperatura, pressão e densidade dos fluidos. A metodologia sequencial nos permite obter configurações espaciais do sistema atômico e estas configurações são consequência da condição termodinâmica do fluido, que é preservada nos cálculos $a b$ initio realizados posteriormente.

Estudos experimentais do espectro do xenônio como impureza num ambiente for- 
mado por argônio foram realizados em uma variedade de condições termodinâmicas [82, 83, 84], desde um regime de baixas densidades até densidades típicas do estado líquido, incluindo a região supercrítica.

Pretendemos explorar diferentes condições termodinâmicas, variando as grandezas temperatura e densidade, atingindo também as condições correspondentes aos estados supercríticos. O espectro eletrônico do átomo de xenônio $\left({ }^{1} S_{0} \rightarrow{ }^{1,3} P\right)$ sob o efeito do meio será calculado e o shift em relação ao átomo isolado (fase gasosa) será obtido onde também observaremos seu comportamento com a variação de densidade. Portanto, este estudo descreve não apenas o shift espectral em uma condição termodinâmica, mas num amplo intervalo de densidades. O caso de baixa densidade é muito desafiador. De fato, enquanto os shifts espectrais aumentam (blue shift) para altas densidades, a energia de transição diminui (red shift) no regime de baixas densidades, segundo as informações experimentais [82]. Estes aspectos são considerados nesse capítulo, cujos resultados também estão em um trabalho publicado no períodico Physics Letters A [85].

\subsection{Simulação clássica Monte Carlo}

Realizamos as simulações Monte Carlo (MC) sob seis diferentes condições termodinâmicas. O ensemble utilizado foi o $N V T$, pois desta forma podemos manter a densidade do sistema constante durante a simulação. Os parâmetros do potencial de Lennard-Jones usados para cada átomo são: $\varepsilon=0.2339 \mathrm{kcal} / \mathrm{mol}, \sigma=3.401 \AA$ para o $\operatorname{argônio~e~} \varepsilon=0.4330 \mathrm{kcal} / \mathrm{mol}, \sigma=3.935 \AA$ A para o xenônio [86]. O sistema $\mathrm{Xe} / \mathrm{Ar}$ é composto de 1 átomo de xenônio mais 500 átomos de argônio dispostos em uma caixa cúbica. A configuração inicial dos átomos na caixa é gerada aleatoriamente e um estágio de termalização seguido de uma simulação com um total de $7.5 \times 10^{7}$ passos MC permite obter um grande número de configurações do sistema $X e / A r$. Cada simulação é realizada para uma densidade fixa, compreendendo um intervalo 
que varia de $0.15 \mathrm{~g} / \mathrm{cm}^{3}$ a $1.4 \mathrm{~g} / \mathrm{cm}^{3}$ e temperaturas entre $93 \mathrm{~K}$ e $300 \mathrm{~K}$. O motivo da escolha destes intervalos de valores em particular é que estão entre as condições termodinâmicas nas quais foram feitas as medidas experimentais nos trabalhos de Jortner et al. [82] para o espectro do sistema $X e / A r$, e que tomamos como suporte experimental para o nosso trabalho.

\subsection{Camadas de solvatação}

Analisamos as funções de distribuição radial de pares $g(r)$ de cada simulação. Para maiores densidades é possível visualizar as camadas de solvatação, que apresentam máximos e mínimos mais pronunciados como mostra a figura 6.1. A integral sob a curva fornece o número de coordenação $N(r)$, que representa a quantidade média de átomos em cada camada de solvatação, formada pelos vizinhos mais próximos ao átomo de xenônio.

Como pode ser visto, o aumento da densidade leva a uma estrutura mais bem definida. No caso $\rho=1.40 \mathrm{~g} / \mathrm{cm}^{3}$ três camadas de solvatação são bem definidas. Essa situação é bem diferente para $\rho=0.26 \mathrm{~g} / \mathrm{cm}^{3}$, onde a estrutura se assemelha à situação de um gás.

Na tabela 6.1 mostramos os valores obtidos para $N(r)$ referentes à primeira camada de solvatação. Estes valores demonstram a dependência de $N(r)$ em relação à densidade do fluido e mostram que o número de átomos na primeira camada cresce com o aumento da densidade, como esperado. Os valores $r_{i}$ e $r_{f}$ na tabela 6.1 demarcam o início e o fim desta camada, vista na figura 6.1. O caso de mais baixa densidade foi omitido devido à dificuldade em serem determinados com precisão. Esta situação está mais próxima da condição de um gás.

Os cálculos de mecânica quântica são realizados na estrutura composta pelo átomo de $X e$ e átomos vizinhos de $A r$. A figura 6.1 e a tabela 6.1 nos auxiliam na escolha da quantidade de átomos de argônio a serem considerados como primeiros 


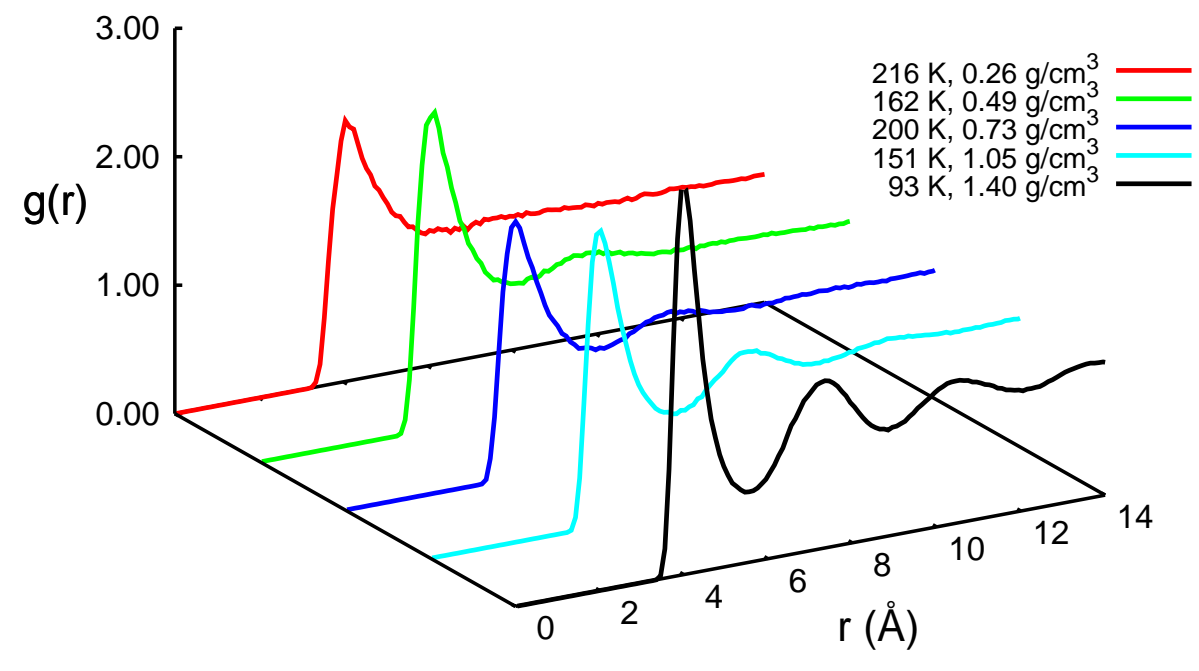

Figura 6.1: Funções de distribuição radial de pares entre os átomos de xenônio e argônio obtidas nas simulações

vizinhos ao átomo de xenônio. De acordo com a tabela, optamos por definir uma estrutura que é um aglomerado composto pelos átomos contidos na primeira camada de solvatação. Na situação de maior densidade, temos três camadas de solvatação bem definidas e à medida que se vai para os regimes de menor densidade o líquido torna-se menos estruturado e as camadas tornam-se menos perceptíveis. Para manter consistência nos cálculos quânticos, mantivemos o mesmo número de átomos de argônio nas diferentes condições termodinâmicas. Portanto, baseando-se nos valores de $\mathrm{N}(\mathrm{r})$ mostrados na tabela 6.1, separamos estruturas que formam agregados compostos de 14 átomos, um de xenônio envolvido por 13 átomos de argônio, o que corresponde às situações próximas das densidades de 1.05 e $1.40 \mathrm{~g} / \mathrm{cm}^{3}$. A figura 6.2 mostra a sobreposição de diferentes configurações para o caso $1.40 \mathrm{~g} / \mathrm{cm}^{3}$, onde se vê a cavidade formada em torno do átomo de xenônio. Um total de 150 configurações 
Tabela 6.1: Número de coordenação entre átomos na primeira camada de solvatação e os valores de início $r_{i}$ e final $r_{f}$ da primeira camada de solvatação.

\begin{tabular}{cccc}
\hline \hline Temperatura (Kelvin) & Densidade $\left(\mathrm{g} / \mathrm{cm}^{3}\right)$ & $N(r)$ & $r_{i}-r_{f}(\AA)$ \\
\hline 216 & 0.26 & 5.04 & $3.35-6.50$ \\
162 & 0.49 & 8.41 & $3.35-6.07$ \\
200 & 0.73 & 10.07 & $3.35-6.04$ \\
151 & 1.05 & 12.92 & $3.35-5.78$ \\
93 & 1.40 & 14.62 & $3.45-5.51$ \\
\hline \hline
\end{tabular}

estatisticamente descorrelacionadas foram separadas para serem submetidas aos cálculos do espectro. Este procedimento segue-se para cada condição termodinâmica estudada, portanto um total de 900 cálculos são realizados para obter o espectro e assegurar a convergência do resultado. Uma alternativa simples para o estudo de átomos em meios fluidos é o chamado modelo de bolha (bubble model) [87, 88]. Nesse caso, um ingrediente importante é o tamanho da bolha, ou cavidade, onde reside o átomo de impureza (soluto). A figura 6.2 pode ser útil mostrando nesse caso uma bolha de raio igual a 3.4, que pouco muda com a condição termodinâmica.

\subsection{Cálculo do espectro eletrônico}

Estudos experimentais no sistema $X e / A r$ têm uma grande motivação na compreensão de estados excitados de líquidos e propriedades de excitons [83]. Assim, uma maior ênfase foi dada aos estados tripletos. Nesta tese, tanto o tripleto como o singleto foram considerados. A discussão, no entanto, será maior para os estados tripletos. Portanto, foi considerado como objetivo inicial o cálculo do espectro do xenônio para descrever a transição da absorção ${ }^{1} S_{0} \rightarrow{ }^{3} \mathrm{P}$ em ambiente formado pelo argônio. Os resultados experimentais são bandas largas sem resolução entre as possíveis componentes do estado ${ }^{3} P\left({ }^{3} P_{2},{ }^{3} P_{1},{ }^{3} P_{0}\right)$. A dependência do espectro com a densidade do meio é verificada pelo desvio espectral $\delta$ (shift) em relação à 


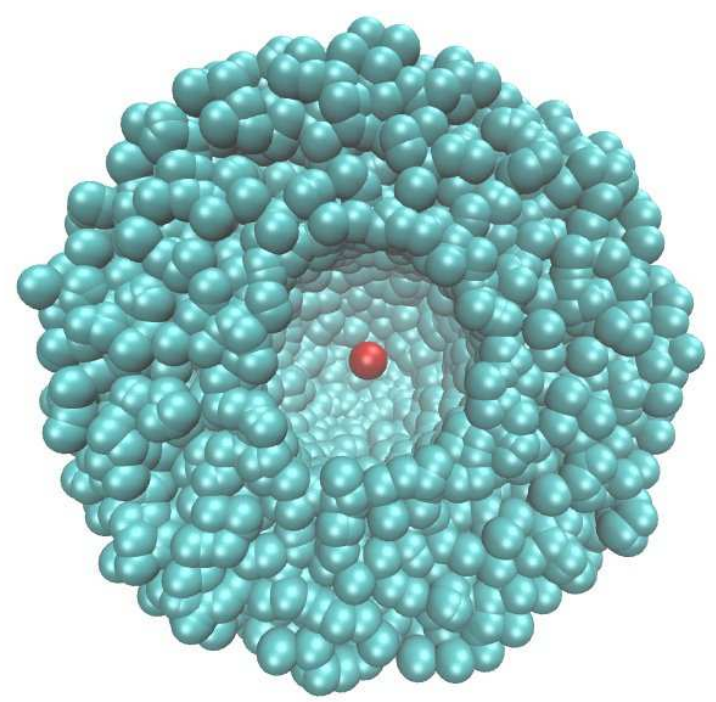

Figura 6.2: Configurações sobrepostas ilustrando a cavidade formada pelo argônio em volta do átomo de Xe (ao centro).

fase gasosa. Os resultados tanto para átomo isolado e em meio foram obtidos por cálculos TD-DFT [62] utilizando o funcional $B 3 L Y P[57,59]$. A base utilizada foi a $S D D$ (Stuttgard/Dresden) potencial de caroço efetivo ou ECP (effective core potential) [90, 89], utilizada para átomos de elevado número atômico e que considera correção relativística para a energia. Esta base considera de forma aproximada os elétrons das camadas mais internas (o "caroço"), e trata explicitamente somente os elétrons de valência [43]. O uso desta base torna-se vantajoso do ponto de vista computacional, já que o custo escala com $Z^{6}$ (Z é o número atômico). Os cálculos de espectro foram realizados utilizando o programa Gaussian 09 [91].

A transição ${ }^{1} S_{0} \rightarrow{ }^{3} \mathrm{P}$ calculada para átomo isolado ocorre em $149 \mathrm{~nm}$ (8.339 eV), em boa concordância com o valor experimental 147 nm [83]. Para o cálculo do shift do deslocamento ou desvio da transição, consideramos o valor da média convergida das 150 configurações obtidas nas condições termodinâmicas já mencio- 
nadas. Primeiramente, para o par $93 \mathrm{~K}$ e $1.4 \mathrm{~g} / \mathrm{cm}^{3}$, o valor da energia de absorção (ou da transição) estatisticamente convergido está em $8.681 \pm 0.080$ eV como pode ser visto na figura 6.3. Obtemos neste caso o shift de $0.341 \pm 0.080 \mathrm{eV}$ deslocado para o azul. Estes valores estão em boa concordância com as medidas de $0.36 \mathrm{eV}$ obtidas na referência [83] para condições de argônio líquido (105 K) e 0.40 eV [82] para $93 \mathrm{~K}$ e $142 \mathrm{~atm}$, correspondendo à densidade de $1.4 \mathrm{~g} / \mathrm{cm}^{3}$.

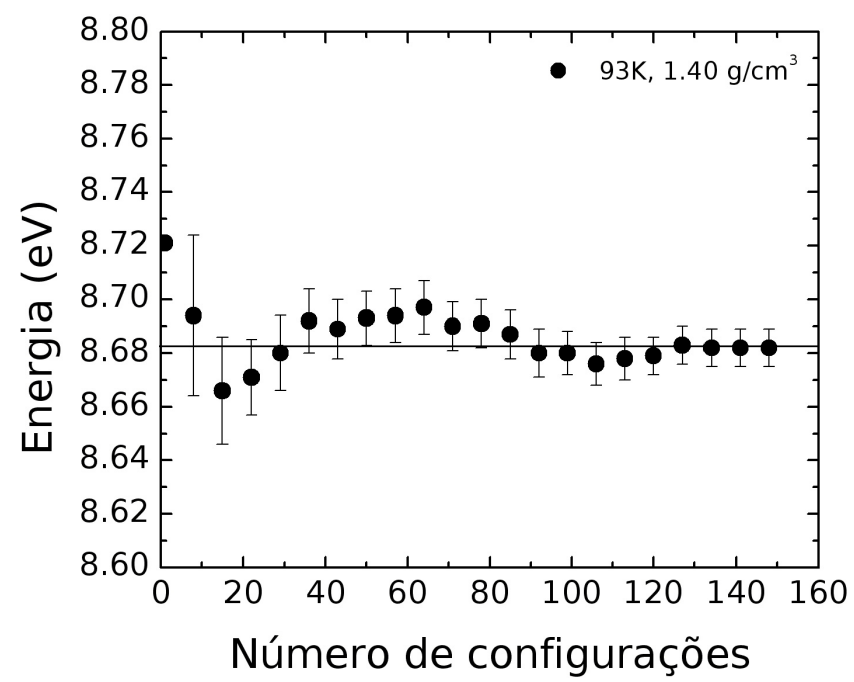

Figura 6.3: Convergência estatística para o cálculo da energia de excitação do xenônio obtida para uma das condições termodinâmicas estudadas neste trabalho.

Para comparação, fizemos os cálculo com dois outros funcionais para a condição termodinâmica de $1.40 \mathrm{~g} / \mathrm{cm}^{3}$. Consideramos dois funcionais destinados a incluir correção de dispersão. São eles: B97-D [92] e $\omega$ B97X-D [93]. Os cálculos foram realizados utilizando as mesmas 150 configurações, onde o primeiro funcional fornece um desvio para azul de $0.377 \pm 0.061 \mathrm{eV}$, próximo ao resultado obtido usando o funcional B3LYP. Para o funcional $\omega$ B97X-D, o shift é um pouco maior, fornecendo $0.425 \pm 0.077 \mathrm{eV}$ também para o azul.

De acordo com a análise populacional, o valor médio da carga no Xe é de $-0.11 e$, 
ou seja, existe uma quantidade de 0.11 e de carga que migra dos átomos de $A r$ para o Xe. Esta quantidade se reduz aproximadamente de cinco vezes para o caso de baixas densidades, como $\rho=0.26 \mathrm{~g} / \mathrm{cm}^{3}$ onde a mudança de carga é de $-0.02 e$.

O desvio padrão nos fornece um valor para a largura de banda em meia altura (full width at half maximum) através da expressão $2 \sigma(2 \ln 2)^{1 / 2}$ e que resulta em $0.19 \mathrm{eV}$, em bom acordo com o valor experimental de $0.23 \mathrm{eV}$ [82]. Como temos um conjunto de configurações fornecendo os resultados para as três transições $p \rightarrow s, \mathrm{o}$ alargamento reflete também a quebra de degenerescência do orbital $5 p$. A separação entre as transições $p \rightarrow s$ variam entre $0.004 \mathrm{eV}$ e $0.10 \mathrm{eV}$ dependendo da densidade.

Seguimos agora para o estudo do comportamento do espectro em função da densidade e então consideramos o intervalo de $0.15 \mathrm{~g} / \mathrm{cm}^{3}$ a $1.40 \mathrm{~g} / \mathrm{cm}^{3}$. Experimentalmente, onde se fez o estudo do espectro do sistema $X e / A r$, este intervalo compreende os estados de fase gasosa, líquida e atinge também as condições supercríticas do argônio [82]. Os resultados obtidos por nós para o desvio em função da densidade estão mostrados na figura 6.4, e apresentam um acordo qualitativo com os resultados experimentais [82], descrevendo um crescimento do $\delta$ com a densidade do fluido. A figura 6.6 mostra o comportamento do desvio espectral em relação à variação de densidade obtidos em experimentos [82].

Além da boa descrição do comportamento do deslocamento espectral com a densidade, verificamos que os resultados quantitativos também têm bom acordo. Por exemplo, para a densidade $\rho=1.05 \mathrm{~g} / \mathrm{cm}^{3}$ obtivemos o valor de $1320 \mathrm{~cm}^{-1}$ $(0.164 \mathrm{eV})$, em bom acordo com o $\delta$ experimental de $1400 \mathrm{~cm}^{-1}[82,84]$ e em $\rho=0.49 \mathrm{~g} / \mathrm{cm}^{3}$ o valor é em torno de $500 \mathrm{~cm}^{-1}$, também próximo do valor medido de $400 \mathrm{~cm}^{-1}$.

Em situações de baixas densidades como é o caso de $\rho=0.26 \mathrm{~g} / \mathrm{cm}^{3}$, nós obtivemos um $\delta$ para azul com valor médio de $200 \mathrm{~cm}^{-1}$, ou seja, a tendência de se aproximar para o valor de fase gasosa (shift nulo). Os resultados experimentais 

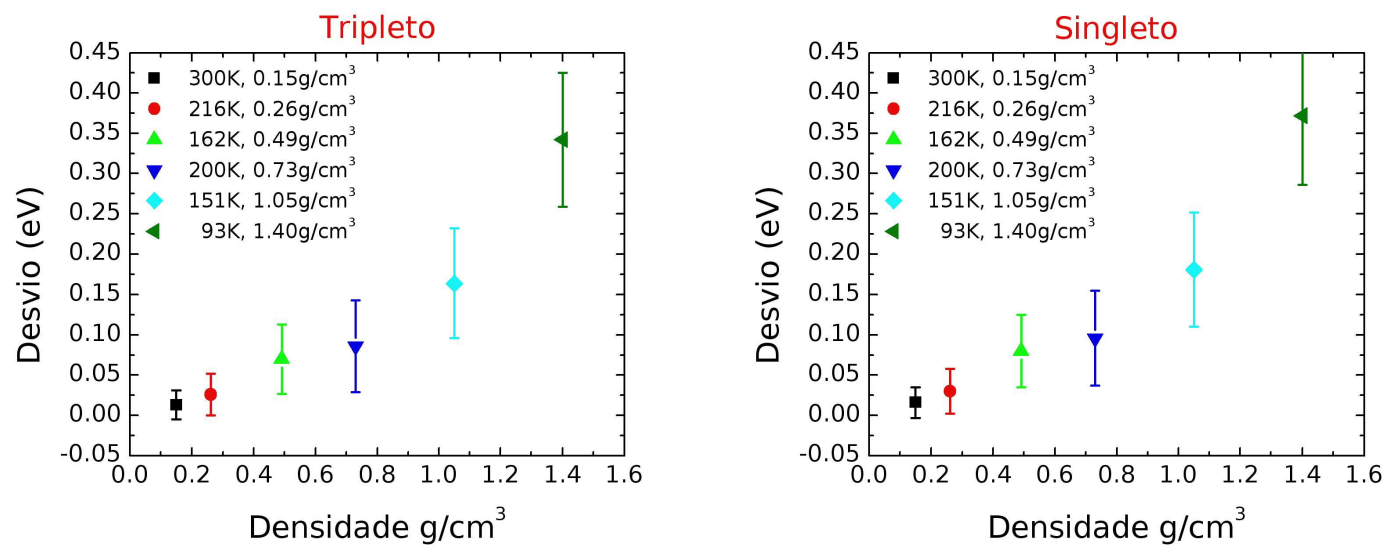

Figura 6.4: Desvio do espectro do xenônio em argônio em relação à fase gasosa, à esquerda para estados tripleto e direita para singleto.

$[82,84]$ apresentam para regimes de densidade baixa valores proxímos a zero e também mostram um pequeno shift para o vermelho.

Apresentamos na figura 6.5 os histogramas de ocorrência dos valores dos shifts calculados. Nestes histogramas são considerados os casos de maior e menor densidade. Na mais baixa densidade considerada aqui $\left(0.15 \mathrm{~g} / \mathrm{cm}^{3}\right)$, apresentado à esquerda o histograma apresenta um perfil assimétrico com um valor médio diferente do valor mais provável, sendo que este último deve ser associado ao experimental. O histograma apresenta o máximo em torno de zero, no entanto valores negativos tem ocorrência apreciável indicando um desvio para vermelho, também obtido por nossos resultados no regime de baixas densidades. Para os casos onde a densidade é maior, esta assimetria não se mostra no histograma como se vê na figura 6.5 (à direita) e a diferença entre valor mais provável e o valor médio torna-se irrelevante para comparação com o experimento.

Finalizamos este capítulo com um sumário dos nossos resultados; o uso do procedimento sequencial combinando simulações MC e cálculos de mecânica quântica se mostrou viável no estudo de estruturas, propriedades eletrônicas e desvios espectrais em fluidos de gases nobres. Os resultados apresentados aqui são consistentes com 

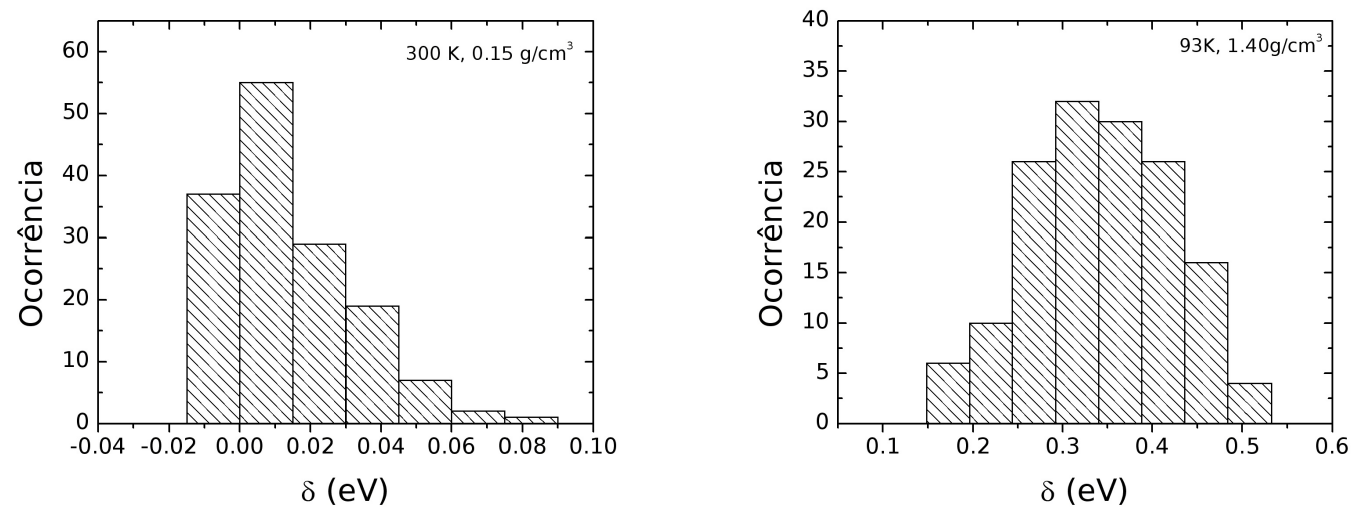

Figura 6.5: Distribuição dos valores dos shifts $\delta$ calculados. $O$ da esquerda para densidade de $0.15 \mathrm{~g} / \mathrm{cm}^{3}$ e direita corresponde à $1.40 \mathrm{~g} / \mathrm{cm}^{3}$.

as observações experimentais nas diversas condições termodinâmicas consideradas, especialmente em variações da densidade, incluindo a região de fluido supercrítico. A ênfase aqui tem sido a descrição do desvio espectral da excitação $(5 p \rightarrow 6 s)$ do átomo de xenônio em argônio. Os resultados reproduzem bem a dependência do desvio espectral com a densisdade do fluido, apresentando bons resultados quantitativos para os casos de baixas, intermediárias e altas densidades. 


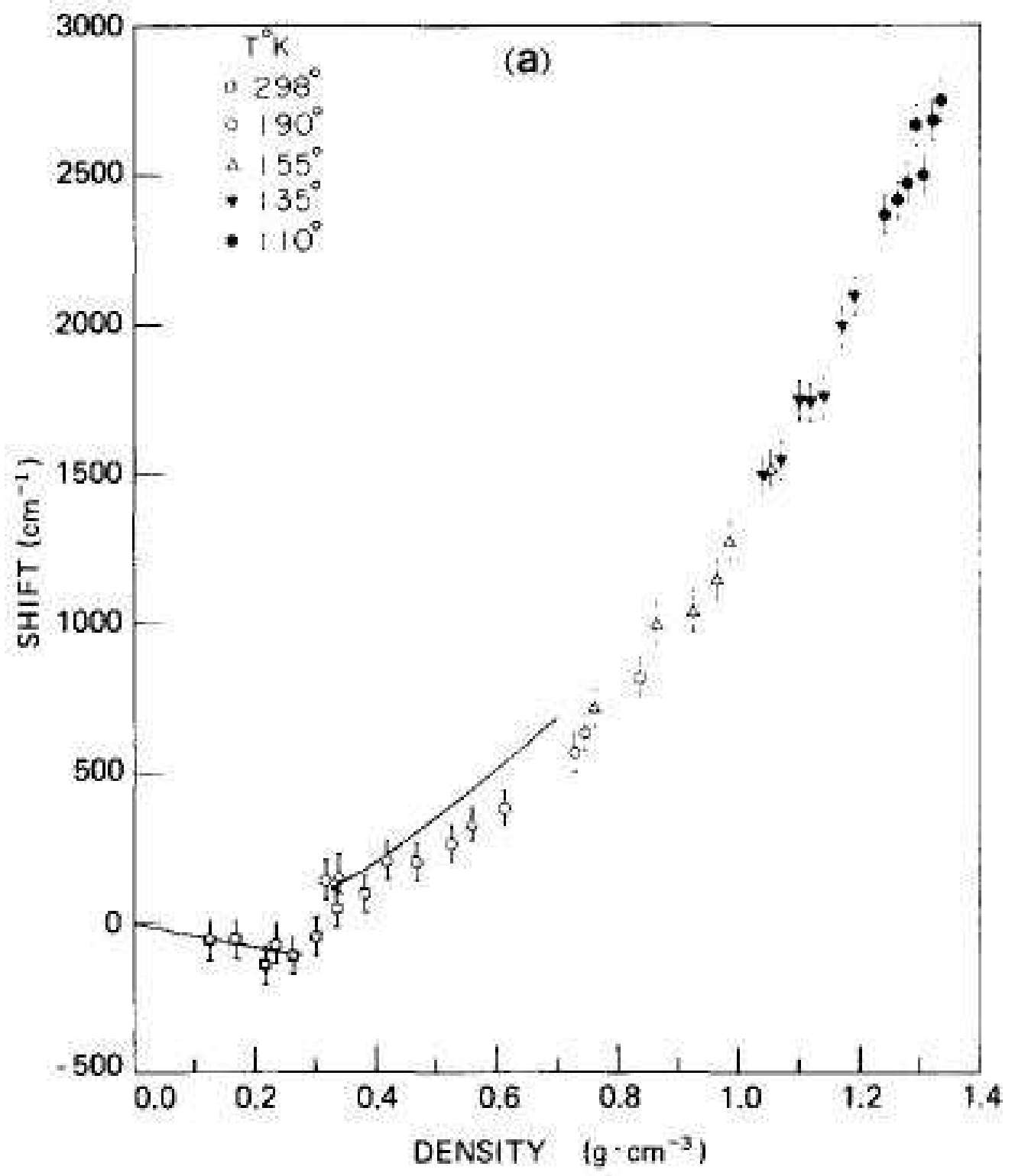

Figura 6.6: Dependência do shift com a densidade, figura retirada de [82]. 


\section{Capítulo 7}

\section{Espectro Eletrônico da}

\section{Paranitroanilina em Fluido}

\section{Supercrítico: $\mathrm{H}_{2} \mathrm{O}$ e $\mathrm{CO}_{2}$}

Neste capítulo apresentamos o estudo do espectro eletrônico da molécula paranitroanilina (PNA) em fluido supercrítico. A água e o dióxido de carbono são utilizados como solventes e, no caso da água, também consideramos em condições normais. A água e o $\mathrm{CO}_{2}$ são uma das substâncias mais estudadas sob condições supercríticas.

\subsection{PNA em água supercrítica e água normal}

A PNA tem sido amplamente estudada devido às suas propriedades de ótica não linear que envolvem a polarizabilidade e hiperpolarizabilidades destes compostos. Além disso, possui uma das estruturas mais simples entre as moléculas com tais propriedades (figura 7.1). A estrutura da PNA compõe-se de um grupo $\mathrm{NH}_{2}$ (amina) e um grupo $\mathrm{NO}_{2}$ (nitro) ligados por um anel benzênico. Esses grupos se caracterizam como doador e aceitador de elétrons. A transição eletrônica mais característica da 
PNA envolve uma transferência de carga que dá origem ao aumento do dipolo e da hiperpolarizabilidade, acarretando o seu interesse em fotônica. Além disso, nestes dois grupos podem ocorrer a formação de ligações de hidrogênio com moléculas do solvente e pretendemos verificar se tais interações ocorrem em água na condição supercrítica e como afetam seu espectro de absorção eletrônico. A existência dessas ligações afetam a transferência de carga do sítio doador ao aceitador e a compreensão mais detalhada deste aspecto é importante.

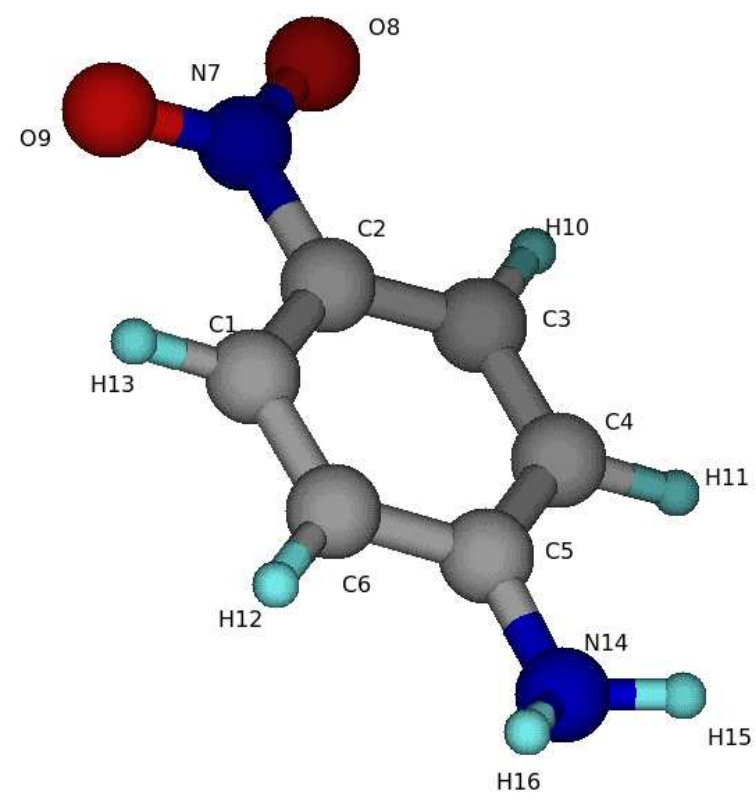

Figura 7.1: Estrutura otimizada da paranitroanilina.

Estudos experimentais em fase gasosa mostram que a PNA apresenta uma única banda intensa de absorção na região do visível e ultravioleta localizada em $292 \mathrm{~nm}$ [94]. Medidas realizadas em meio solvente mostram que seu espectro tem forte dependência com a polaridade do meio [95, 96, 97, 98] como esperado da discussão acima. Neste capítulo vamos estudar a estrutura eletrônica da PNA em meio sol- 
vente. Vamos assim, considerar seu espectro em água normal, em água supercrítica e em $\mathrm{CO}_{2}$ supercrítico. Analisaremos em detalhe as ligações de hidrogênio no caso da água. Vamos observar as mudanças provocadas pela água nas duas condições termodinâmicas. Embora neste trabalho a ênfase esteja nos fluidos supercríticos, a consideração de água normal é interessante pois a comparação entre os dois casos enfatiza a especificidade do caso supercrítico.

Após realizar as simulações MC em água supercrítica, será feita a análise da formação das ligações de hidrogênios entre a PNA e as moléculas de água. Em seguida, configurações estatisticamente descorrelacionadas serão selecionadas para os cálculos de espectro eletrônico em meio solvente. O espectro experimental da PNA foi medido em condições supercríticas $\left(T=653 \mathrm{~K}, \rho=0.12 \mathrm{~g} / \mathrm{cm}^{3}\right.$ a $\left.0.23 \mathrm{~g} / \mathrm{cm}^{3}\right)$ e mostra um máximo em $309 \mathrm{~nm}$, portanto deslocado para o vermelho [32] em relação à fase gasosa. Porém este deslocamento é menor do que o observado em água nas condições normais de temperatura, pressão e densidade $\left(298 \mathrm{~K}, 1 \mathrm{~atm}, 1 \mathrm{~g} / \mathrm{cm}^{3}\right)$. Terminamos o capítulo considerando como solvente o dióxido de carbono, onde estudamos o espectro da PNA neste solvente em condição supercrítica

\subsubsection{Simulação em água supercrítica e normal}

O potencial utilizado para a água na simulação Monte Carlo foi o SPC/E [99] cujos valores para o ponto crítico da água apresentam bom acordo com os valores experimentais [100]. As condições termodinâmicas da simulação correspondentes ao estado supercrítico foram $T=655 \mathrm{~K}$ e $\rho=0.12 \mathrm{~g} / \mathrm{cm}^{3}$, de acordo com as condições experimentais consideradas em [32]. A simulação em água supercrítica foi realizada no ensemble $N V T$, pois assim temos garantia de manter a densidade constante. Para a água normal (condições ambiente), o modelo para a água também é o SPC/E e condições normais de temperatura e pressão $(T=298 \mathrm{~K}$ e $P=1 \mathrm{~atm})$ no ensemble NPT. A densidade obtida na simulação em água normal foi de $1.02 \pm 0.01 \mathrm{~g} / \mathrm{cm}^{3}$. 
Foram utilizadas 1 PNA + 500 moléculas de água. Os parâmetros do potencial de Lennard-Jones para a PNA foram obtidos das referências apresentados em [101, 102]. Foram realizados um total de $6 \times 10^{6}$ passos MC na etapa de termalização e $1.5 \times 10^{8}$ passos MC na etapa de equilíbrio. As simulações foram feitas utilizando o programa DICE [65].

Durante toda a simulação, a geometria da PNA é mantida fixa, na geometria de mínima energia (figura 7.1), obtida por cálculo MP2 (teoria de perturbação de segunda ordem) utilizando a base $a u g-c c-p V D Z$. Para incluir o efeito do solvente na estrutura molecular, esta geometria foi otimizada sob efeito do modelo contínuo polarizável PCM. A constante dielétrica da água possui dependência com as condições termodinâmicas $[103,104]$. Como se pode ver na figura 7.2 , a constante dielétrica da água é bastante reduzida sob condições supercríticas.

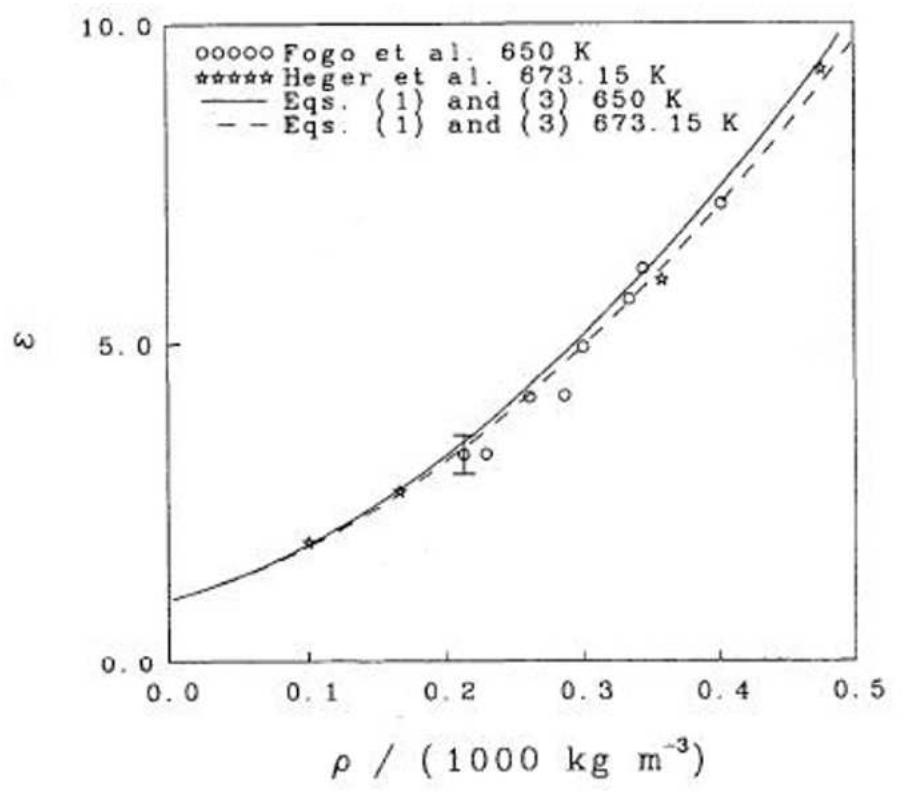

Figura 7.2: Dependência da constante dielétrica da água com a densidade a temperaturas supercríticas. A densidade crítica $\rho_{c}$ da água é de $0.322 \mathrm{~g} / \mathrm{cm}^{3}$. Figura extraída da referência [103]. 
Portanto consideramos uma constante dielétrica diferente em água normal e supercrítica. Para a simulação em água supercrítica, otimizamos a geometria da PNA em PCM com o valor $\epsilon=2.66$, sugerido por Pomelli e Tomasi [105] e que corresponde às condições de temperatura e densidade similares àquelas usadas em nossas simulações da água supercrítica. Esta consideração também foi feita no cálculo das cargas da PNA utilizadas na simulação MC. As cargas foram determinadas pelo método de ajuste do potencial eletrostático CHELPG [106] também em PCM e mesma constante dielétrica. Com isto, esperamos incluir o efeito de polarização do meio sobre a molécula PNA, mas que deve ser menos pronunciado que o efeito causado pela água em condições normais, onde se tem uma constante dielétrica maior $(\epsilon=78.36)$. As cargas obtidas são mostradas na tabela 7.1 da página 57. A geometria e as cargas da PNA utilizadas na simulação em água normal foram obtidas utilizando o mesmo procedimento, ou seja, incluindo o efeito da polarização do meio contínuo. Estes cálculos foram realizados usando o programa Gaussian 09 [91].

As funções de distribuição radial de pares $g(r)$ são mostradas na figura 7.3, e correspondem às $g(r)$ entre a PNA e as moléculas de água. Nos gráficos estão indicados quais os pares de átomos foram considerados para o cálculo da $g(r)$. Como estamos interessados nas formações das ligações de hidrogênio entre a PNA e a água, mostramos as funções $g(r)$ referentes aos átomos que compõem os grupos $\mathrm{NO}_{2}$ (oxigênios), $\mathrm{NH}_{2}$ (hidrogênios) e os átomos da água. É possível ver a diferença bastante significativa entre o primeiro pico da $g(r)$ em água supercrítica, que se torna menos definido que na água normal. No entanto, o intervalo onde estes picos ocorrem são aproximadamente os mesmos, em torno de 1.5 a 2.5 para as $g(r)$ entre os oxigênios da PNA e hidrogênios da água. Este intervalo também é observado para a $g(r)$ entre os hidrogênio da PNA e os oxigênios da água. A integral sob o primeiro pico fornece o número de coordenação, ou seja, o número médio de moléculas de água próximas aos grupos $\mathrm{NO}_{2}$ e $\mathrm{NH}_{2}$. Para a água supercrítica, este valor de $\mathrm{N}(r)$ é de 
0.22 e 0.20 no grupo nitro e amina, respectivamente. Para a água normal, o número de coordenação fornece 1.2 e 0.88 . Estes valores de $N(r)$ indicam um decréscimo da probabilidade de se encontrar moléculas de água próximas aos grupos nitro e amina da PNA, o que é esperado devido à diminuição da densidade no caso supercrítico.
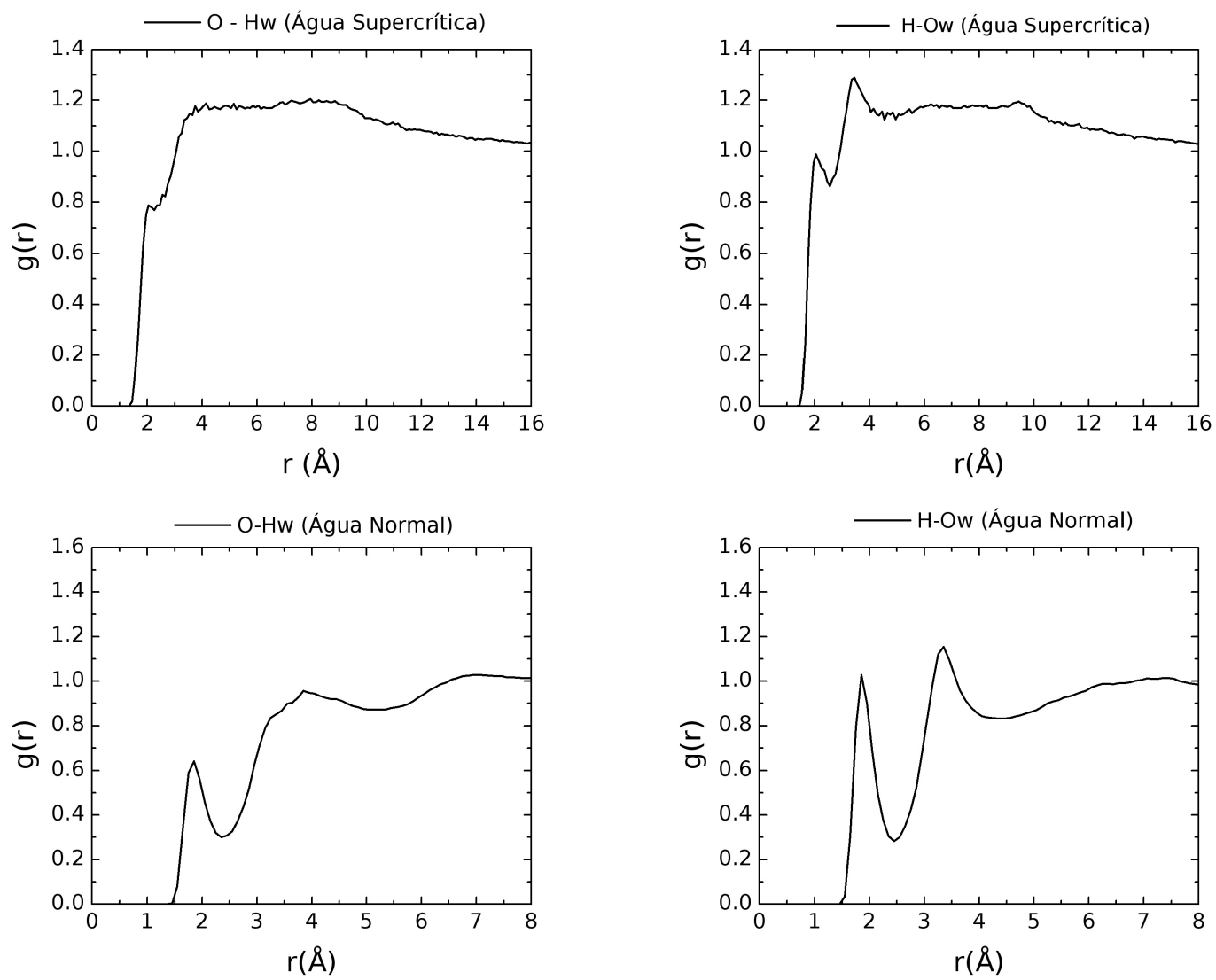

Figura 7.3: Funções de distribuição radial de pares entre a PNA e a água. Do lado esquerdo estão os gráficos referentes às $g(r)$ entre os átomos de oxigênio do grupo $\mathrm{NO}_{2}$ na PNA e os hidrogênios da água, indicados por O-Hw. À direita são mostrados os gráficos correspondentes às $g(r)$ entre os hidrogênios do grupo $\mathrm{NH}_{2}$ da PNA e o oxigênio da água, indicados por $\mathrm{H}-\mathrm{Ow}$. 
Tabela 7.1: Cargas atômicas (em unidades atômicas) da PNA isolada e polarizada; abaixo estão os valores do momento de dipolo (em Debye). As cargas foram obtidas utilizando o método CHELPG em PCM, com as constantes dielétricas indicadas em parênteses.

\begin{tabular}{cccc}
\hline \hline Átomo & Isolada & Água-SC $(\epsilon=2.66)$ & Água $(\epsilon=78.36)$ \\
\hline C1 & -0.212926 & -0.243623 & -0.250979 \\
C2 & 0.155520 & 0.157963 & 0.153850 \\
C3 & -0.212926 & -0.243623 & -0.250979 \\
C4 & -0.134627 & -0.123061 & -0.145771 \\
C5 & 0.290608 & 0.299488 & 0.356356 \\
C6 & -0.134627 & -0.123061 & -0.145771 \\
N7 & 0.529510 & 0.575520 & 0.597192 \\
O8 & -0.365615 & -0.403492 & -0.433859 \\
O9 & -0.365615 & -0.403492 & -0.433859 \\
H10 & 0.144138 & 0.159679 & 0.169772 \\
H11 & 0.132070 & 0.139800 & 0.153550 \\
H12 & 0.132070 & 0.139800 & 0.153550 \\
H13 & 0.144138 & 0.159679 & 0.169772 \\
N14 & -0.723124 & -0.773465 & -0.844320 \\
H15 & 0.310703 & 0.340944 & 0.375748 \\
H16 & 0.310703 & 0.340944 & 0.375748 \\
$\mu(D)$ & 6.16 & 7.33 & 8.58 \\
\hline \hline
\end{tabular}

\subsubsection{Estatística das ligações de hidrogênio}

A formação de ligações de hidrogênio (HB - Hydrogen Bond) em água é fortemente influenciada pela temperatura, pressão e densidade do fluido. Estudos por difração de neutrons [107] indicam que em condições supercríticas a água perde a sua coordenação tetraédrica, que é formada por uma rede de ligações de hidrogênio, como é vista em condições normais. Porém, evidências experimentais também sugerem que as ligações ainda persistem e não são negligenciáveis nas condições supercríticas $[28,108,109]$. A formação de ligações de hidrogênio não somente em água pura, mas entre soluto e a água também são de interesse. O estudo teórico por simulação MC da acetona em água supercrítica [30] mostra que as configurações 
que ocorrem com maior frequência apresentam nenhuma ou apenas uma ligação de hidrogênio entre a acetona e a água. No entanto, em água normal as configurações com uma e duas ligações são observadas com maior frequência.

A análise da formação das $H B$ entre a água e a PNA foi feita nos grupos $\mathrm{NO}_{2}$ e $\mathrm{NH}_{2}$. Aplicamos um critério geométrico e energético [29, 30, 27], o geométrico diz respeito à distância entre as moléculas de água e o soluto e o critério energético leva em consideração uma distribuição de energia entre pares de moléculas. O uso do critério é para a ocorrência das ligações entre os átomos de oxigênio da PNA (O8 e O9 na figura 7.1) quando estes atuam como doadores na ligação e a água como aceitadora das ligações. O mesmo é feito para os átomos de hidrogênio da PNA, mas neste caso a água é doadora das $H B$ e a PNA é receptora das ligações nos hidrogênios H15 e H16 (figura 7.1). Um esquema de uma configuração com a PNA formando duas HB com a água é mostrado na figura 7.4.

Pretendemos obter uma estatística de ocorrência de ligações de hidrogênio entre a PNA e as moléculas de água. Esta análise também é feita com a PNA em água normal e comparamos os resultados nas duas condições termodinâmicas. Com isto, também podemos obter um conjunto de configurações onde possíveis $H B$ estejam ocorrendo, e usar estas configurações para os cálculos de espectro de absorção e verificar sua contribuição para o comportamento do espectro eletrônico da PNA em água supercrítica. O critério utilizado aqui para identificar as configurações onde ocorram as ligações é de $r \leq 3.5 \AA$ para distância entre os átomos que formam a ligação, o ângulo é $\leq 35^{\circ}$ (em amarelo na figura 7.4). O critério energético é de energias menores que $-3.0 \mathrm{kcal} / \mathrm{mol}$. Na figura 7.5 são mostrados os histogramas da ocorrência das energias de interação entre a PNA e as moléculas de água obtidas em simulações de água supercrítica (esquerda) e água em condições normais (à direita). No histograma para a água em condições normais existe uma região de ocorrências com energias menores que $-3.0 \mathrm{kcal} / \mathrm{mol}$. Para a água supercrítica esta região não 


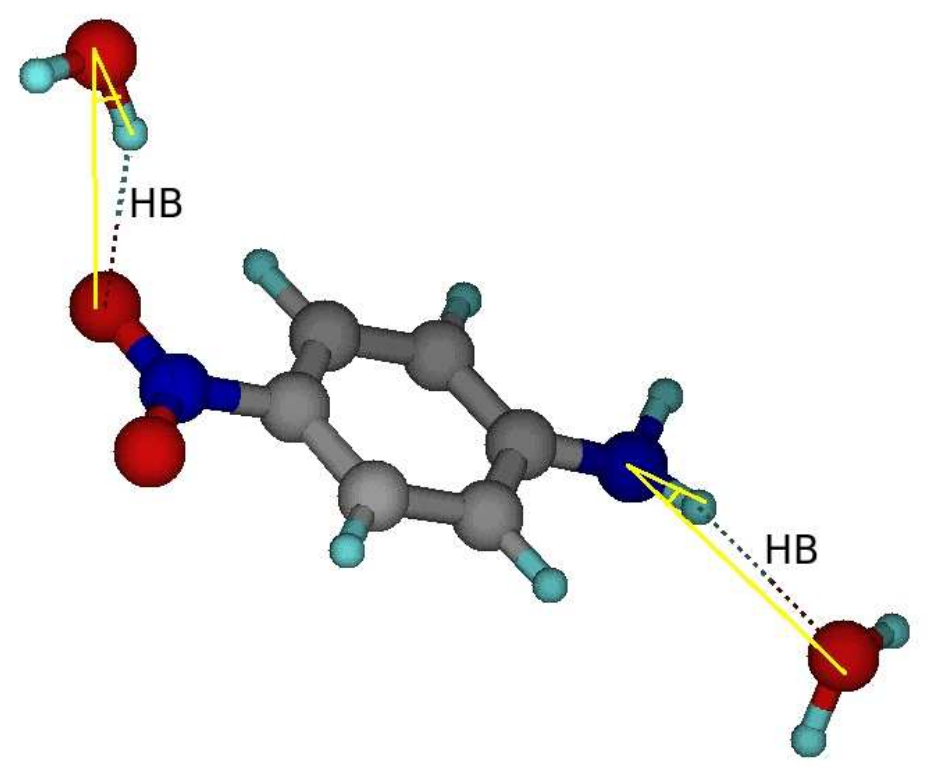

Figura 7.4: Estrutura de uma configuração da PNA formando ligações de hidrogênio com a água. A distância mostrada em pontilhados e os ângulos em linha preta são os locais de aplicação do crítério geométrico.

está bem definida mas ainda é possível observar um "ombro" nesta mesma região de energias, indicando que as ligações ainda estão presentes neste intervalo de energias em água supercrítica. Potanto o critério será o mesmo, tanto para as condições termodinâmicas de água normal quanto para o caso de água supercrítica.

No total foram analisadas 300 configurações estatisticamente descorrelacionadas da PNA em água supercrítica. Destas 300 configurações, um total de 166 (55 \%) não formam ligações de hidrogênio. Das configurações restantes (um total de 134), 107 (36 \%) apresentam uma ligação, que pode ocorrer tanto no grupo $\mathrm{NO}_{2}$ como no $\mathrm{NH}_{2}$. Seguindo a contagem, 24 (8\%) configurações formam 2 ligações e somente 3 (3\%) configurações formam 3 ligações de hidrogênio entre a PNA e a água. Novamente, enfatizamos que esta contagem inclui ligações que se formam em quaisquer dos grupos, $\mathrm{NO}_{2}$ e $\mathrm{NH}_{2}$. Na tabela apresentamos também a comparação da esta- 
tística das ligações de hidrogênio da PNA em água supercrítica e água em condições normais.

Tabela 7.2: Estatística da ocorrência de ligações de hidrogênio em água supercrítica e água em condições normais. Na tabela estão apresentadas a quantidade de ligações $\left(N_{H B}\right)$, em quantas configurações esta quantidade ocorre e a sua porcentagem. Estas ligações hidrogênio ocorrem no grupo $\mathrm{NO}_{2}$ e/ou $\mathrm{NH}_{2}$.

\begin{tabular}{|c|c|c|c|c|}
\hline \multirow[b]{2}{*}{$N_{H B}$} & \multicolumn{2}{|c|}{ Água Supercrítica } & \multicolumn{2}{|c|}{ Água } \\
\hline & $N^{o}$ de conf. & Ocorrência (\%) & $N^{o}$ de conf. & Ocorrência (\%) \\
\hline 0 & 166 & 55 & 3 & 1 \\
\hline 1 & 107 & 36 & 19 & 6.3 \\
\hline 2 & 24 & 8 & 86 & 28.7 \\
\hline 3 & 3 & 3 & 104 & 34.7 \\
\hline 4 & 0 & 0 & 76 & 25.3 \\
\hline 5 & 0 & 0 & 12 & 4 \\
\hline média & \multicolumn{2}{|c|}{$\langle 0.55\rangle$} & \multicolumn{2}{|c|}{$\langle 2.89\rangle$} \\
\hline
\end{tabular}

Observamos que em condições supercríticas há uma diminuição significativa na quantidade de ligações de hidrogênio entre a PNA e a água. Porém, mesmo no regime de alta temperatura e baixa densidade as ligações ainda persistem. Por comparação entre as duas situações mostradas na tabela 7.2, vemos que se invertem as
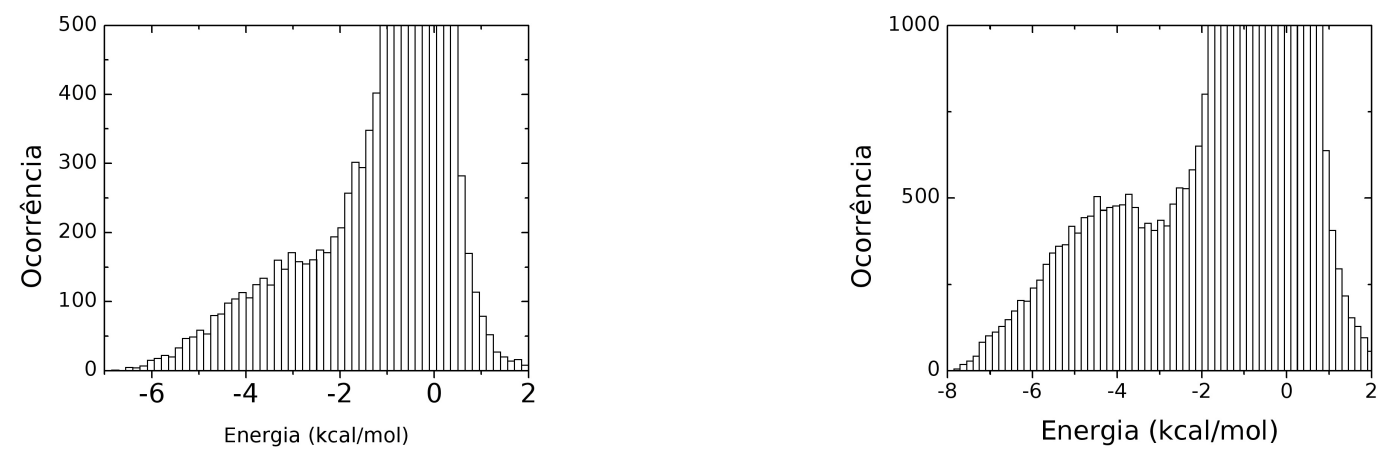

Figura 7.5: Histograma de distribuição das energias de interação entre a PNA e moléculas de água. À esquerda para água supercrítica e direita a água em condições normais. 
ocorrências de ligações de hidrogênio, onde na condição supercrítica a maior ocorrência é para configurações com 1 ligação, enquanto que para água em condições normais, as configurações com maior ocorrência são aquelas onde se formam 3 ligações de hidrogênio. Na média, ocorrem 0.6 ligações na condição supercrítica, bem inferior ao valor médio de 2.9 ligações no caso de condição normal da água.

\subsubsection{Espectro eletrônico da PNA}

O espectro eletrônico de absorção em fase gasosa medido para a PNA apresenta uma intensa transição em torno de $292 \mathrm{~nm}(4.25 \mathrm{eV})$ [94, 96], e é caracterizada por uma transferência de carga. Um aspecto fundamental que tem merecido atenção é a participação das ligações de hidrogênio no caso da PNA em água supercritica. Oka e Kajimoto [32] estudaram experimentalmente o espectro da PNA em água supercrítica, concluindo que a formação das $H B$ nos grupos nitro e amina são negligenciáveis e que o desvio espectral na água supercrítica é dominado pelo efeito de bulk (constante dielétrica da água supercrítica).

Para estudar esses aspectos, iniciamos com a consideração da PNA isolada. Para isso realizamos cálculos do espectro para aferir os resultados fornecidos por alguns funcionais. A tabela 7.3 mostra que dentre os funcionais considerados, o melhor resultado é obtido com o funcional CAM-B3LYP [110], que apresenta a transição de maior intensidade (força de oscilador) em $287.5 \mathrm{~nm}(4.30 \mathrm{eV})$. Este resultado difere do experimental por apenas $0.05 \mathrm{eV}$. Isto está em acordo com a espectativa geral que o funcional CAM-B3LYP é mais adequado para estudar transições que envolvem transferência de carga. Esta transição é do tipo $\pi-\pi^{*}$ e ocorre entre os orbitais HOMO (Highest Occupied Molecular Orbital) e LUMO (Lowest Unoccupied Molecular Orbital) como mostra a figura 7.6. Como pode ser visto nesta figura, há uma transferência de carga do grupo $\mathrm{NH}_{2}$ para o grupo $\mathrm{NO}_{2}$. O funcional CAMB3LYP foi então escolhido para os cálculos de espectro em meio solvente. 
Tabela 7.3: Energias de excitação em nm e força de oscilador entre parênteses, calculadas utilizando diferentes funcionais e base aug-cc-pVDZ. O valor experimental é de 292 $\mathrm{nm}$ [94].

\begin{tabular}{ccccccccc}
\hline \hline & \multicolumn{2}{c}{ B3LYP } & \multicolumn{2}{c}{ BHandHLYP } & \multicolumn{2}{c}{ CAMB3LYP } & \multicolumn{2}{c}{ PBE0 } \\
\hline 1 & 332.4 & $(0.00)$ & 300.8 & $(0.00)$ & 320.4 & $(0.00)$ & 325.4 & $(0.00)$ \\
2 & 320.6 & $(0.31)$ & 279.4 & $(0.37)$ & 287.5 & $(0.36)$ & 308.5 & $(0.33)$ \\
3 & 291.2 & $(0.00)$ & 270.2 & $(0.00)$ & 282.7 & $(0.00)$ & 286.1 & $(0.00)$ \\
\hline \hline
\end{tabular}

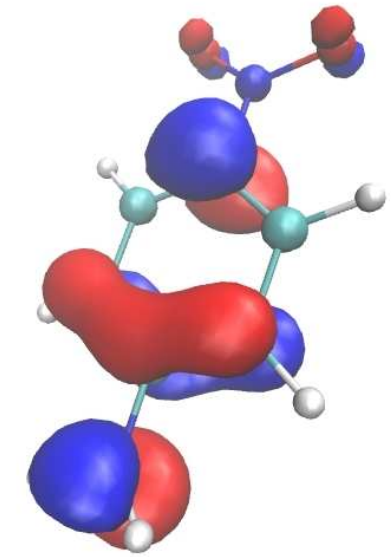

HOMO

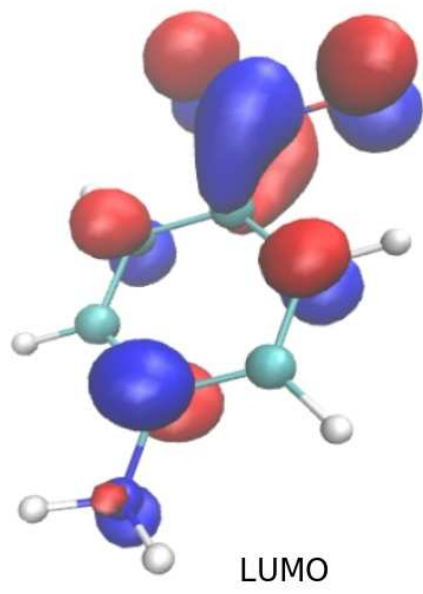

Figura 7.6: Orbitais da PNA envolvidos na transição eletrônica $H O M O(\pi)$ - LUMO $\left(\pi^{*}\right)$.

Após fazer a análise das ligações de hidrogênio, foram separadas 100 configurações estatisticamente descorrelacionadas. Estas configurações são constituídas da PNA e as moléculas de água que formam as ligações de hidrogênio tratadas explicitamente. As demais moléculas de água são tratadas apenas como cargas pontuais. A figura 7.7 mostra a sobreposição das configurações ilustrando os locais de ocorrência das ligações de hidrogênio entre a PNA e a água e a figura 7.8 mostra a situação onde a PNA e duas moléculas de água são tratadas explicitamente e as demais apenas como embedding eletrostático.

Para o cálculo do espectro em solvente, consideramos primeiro a situação onde 


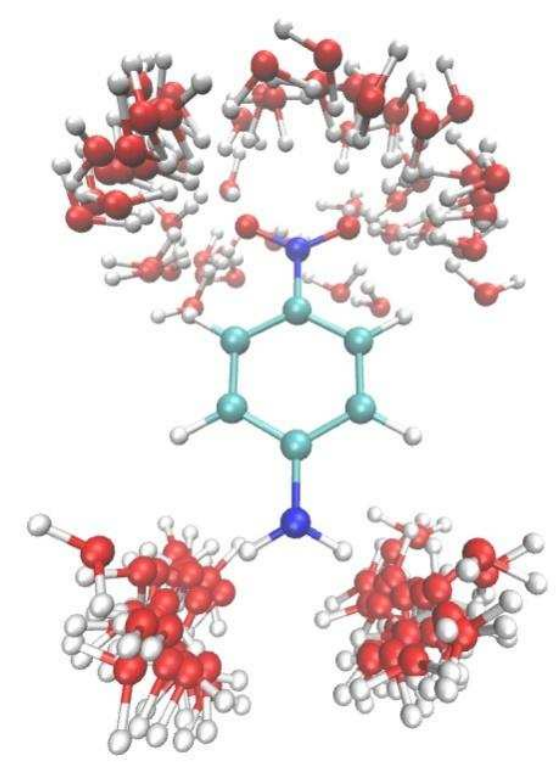

Figura 7.7: Ilustração das configurações que formam ligações de hidrogênio entre a PNA e a água.

as moléculas de água estejam representadas apenas por cargas pontuais (apenas embedding eletrostático). Foram incluídas um total de 350 moléculas de água representandas pelas cargas pontuais. Os resultados experimentais do espectro da PNA em água supercrítica $\left(655 \mathrm{~K}, 0.12 \mathrm{~g} / \mathrm{cm}^{3}\right)$ apontam um máximo em torno de $309 \mathrm{~nm}$ [32] correspondendo a um desvio para vermelho em relação à fase gasosa. Nestas mesmas condições da água supercrítica, nosso resultado para o espectro calculado é de $300 \pm 9 \mathrm{~nm}$ considerando somente o embedding eletrostático. Em seguida, incluímos as moléculas explícitas representadas por aquelas que formam ligações de hidrogênio com a PNA. De acordo com a tabela 7.2, estas configurações possuem em sua maioria uma a duas moléculas explícitas, mais as 350 moléculas como cargas pontuais. A figura 7.8 ilustra uma das configurações onde são representadas duas moléculas de água explícitas mais o embedding eletrostático. Nosso resultado como média convergida sobre 100 configurações é de $305 \pm 9 \mathrm{~nm}$. A tabela 7.4 reúne 
os resultados para comparação e mostra que a maior contribuição para o deslocamento do espectro é causada pelo embedding eletrostático representado pelo modelo discreto de cargas pontuais.

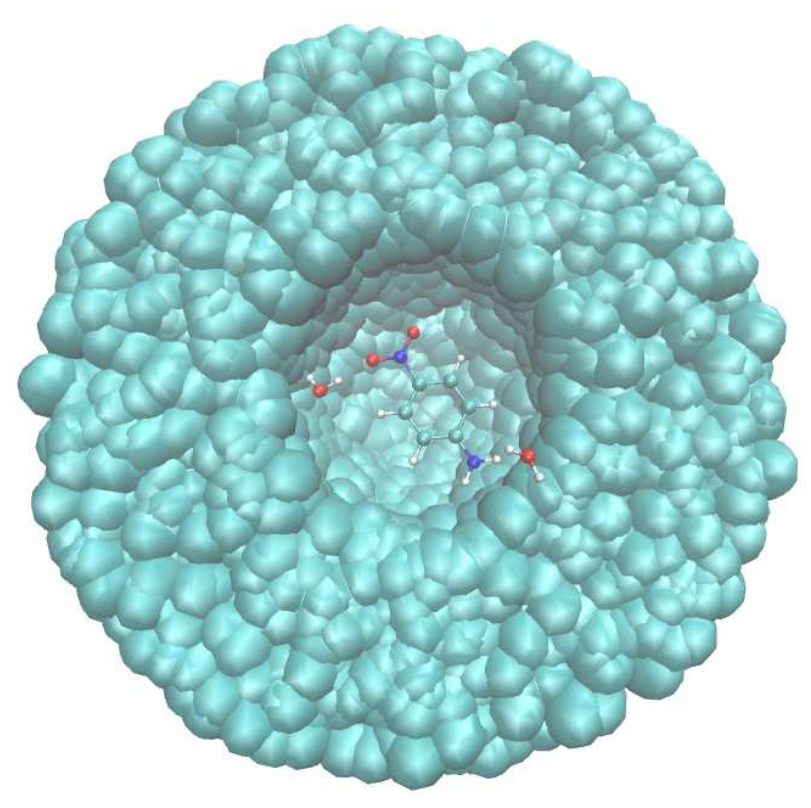

Figura 7.8: Ilustração de uma configuração onde aparecem duas moléculas explícitas ligadas à PNA e o corte transversal do embedding formado pelas cargas pontuais.

Tabela 7.4: Transições eletrônicas calculadas para a PNA isolada e em água supercrítica. Resultados obtidos utilizando TD-DFT com funcional CAM-B3LYP. As abreviações cp se referem à cargas pontuais e HB significa que as moléculas que são incluídas explicitamente, as moléculas que formam ligações de hidrogênio. As moléculas explícitas são aquelas que respeitam o critério de formação das ligações de hidrogênio.

\begin{tabular}{ccc}
\hline \hline \multirow{2}{*}{ Metodologia } & \multicolumn{2}{c}{ Transição em nm (eV) } \\
\cline { 2 - 3 } & Calculado & Experimental $[94,32]$ \\
\hline \hline Isolada & $288(4.30)$ & $292(4.25)$ \\
PNA $+350 \mathrm{cp}$ & $300 \pm 10(4.13)$ & $309(4.01)$ \\
PNA + HB $+350 \mathrm{cp}$ & $305 \pm 10(4.06)$ & $309(4.01)$ \\
\hline \hline
\end{tabular}


Na figura 7.9 temos a convolução do espectro onde todas as transições são incluídas, com um total de 10 transições calculadas para cada configuração. Para comparação, o espectro experimental [32] também é mostrado. A lagura da banda em meia altura obtida por nós é de $83 \mathrm{~nm}$, enquanto que o valor experimental é de $98 \mathrm{~nm}$ (figura 7.9).

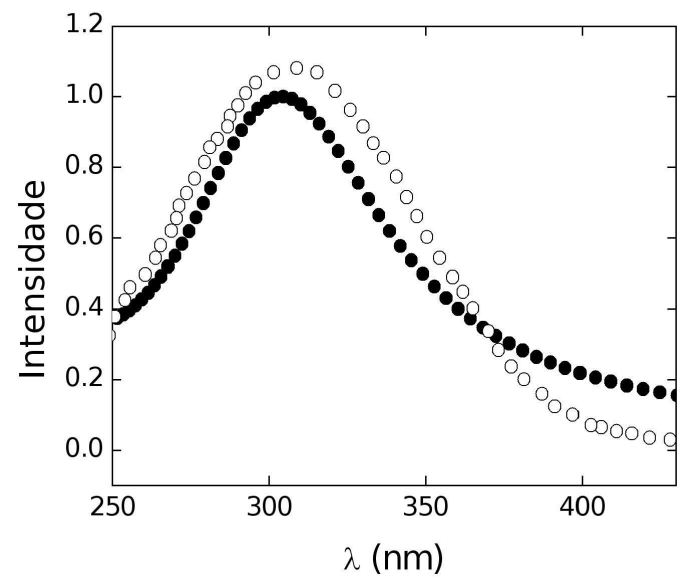

Figura 7.9: Convolução do espectro calculado da PNA em água supercrítica (•) e espectro experimental (०) [32]. A convolução do espectro calculado apresenta um máximo em $304 \mathrm{~nm}$.

Consideramos agora o shift ocorrido no espectro da PNA em água supercrítica em relação ao valor de fase gasosa. O shift observado no espectro experimental está em torno de $17 \mathrm{~nm}$, em excelente concordância com o nosso melhor resultado, que também é $17 \mathrm{~nm}$. Em termos de energia, pode ser visto o shift experimental de $0.24 \mathrm{eV}$ muito bem descrito pelo resultado teórico obtido usando-se as configurações com ligações de hidrogênio no embedding eletrostático. Nossos resultados teóricos mostram a posição da banda um pouco mais energética (por $4 \mathrm{~nm}$ ) mas obtém o shift como $17 \mathrm{~nm}$ em concordância precisa com o valor experimental. Nosso melhor resultado, como esperado, é obtido com o cálculo CAM-B3LYP/aug-cc-pVDZ, considerando a PNA mais as moléculas explícitas que formam ligações de hidrogênio e 
o embedding eletrostático.

Aplicamos também a mesma metodologia utilizando outros dois funcionais que foram usados nos cálculos da molécula isolada como visto na tabela 7.3. Além do CAM-B3LYP, utilizamos os funcionais B3LYP $[57,59]$ e PBE0 [111, 112] para o cálculo do espectro em meio, e os resultados são mostrados na tabela 7.5. Comparando apenas o desvio no espectro em relação à fase gasosa, podemos observar que o funcional CAM-B3LYP de fato forneceu o melhor acordo com o espectro medido. Este acordo acontece tanto para os valores da transição quanto para o desvio do espectro. Os funcionais B3LYP e PBE0 superestimam o comprimento de onda das transições, porém apresentam bons valores para o desvio, sendo o valor de $20 \mathrm{~nm}$ para o B3LYP e $19 \mathrm{~nm}$ para o PBE0.

Tabela 7.5: Valores da transição da PNA em água supercrítica calculadas com os funcionais CAM-B3LYP, B3LYP e PBE0.

\begin{tabular}{ccccc}
\hline \hline \multirow{2}{*}{ Metodologia } & \multicolumn{4}{c}{ Transição em nm (eV) } \\
\cline { 2 - 5 } & CAM-B3LYP & B3LYP & PBE0 & Exp. [94, 32] \\
\hline \hline Isolada & $288(4.30)$ & $321(3.86)$ & $309(4.01)$ & $292(4.25)$ \\
PNA + 350 cp & $300 \pm 10(4.13)$ & $334 \pm 10(3.70)$ & $321 \pm 10(3.86)$ & $309(4.01)$ \\
PNA + HB + 350 cp & $305 \pm 10(4.06)$ & $341 \pm 10(3.64)$ & $328 \pm 10(3.78)$ & $309(4.01)$ \\
\hline \hline
\end{tabular}

Ao considerarmos explicitamente as moléculas de água nos cálculos, obtemos melhor acordo com o espectro medido. Estas moléculas estão presentes tanto no grupo $\mathrm{NH}_{2}$ com no grupo $\mathrm{NO}_{2}$. Achamos agora pertinente considerar também outras duas situações, onde as moléculas explícitas estejam presentes em apenas um dos grupos e não nos dois simultaneamente. Obtivemos o valor de $306 \pm 9 \mathrm{~nm}$ quando as moléculas explícitas estavam presentes formando ligação com o grupo $\mathrm{NO}_{2}$ e o restante como cargas pontuais. Para o caso onde só as moléculas ligadas ao grupo $\mathrm{NH}_{2}$ estavam presentes o resultado foi de $304 \pm 7 \mathrm{~nm}$. Com isto, pudemos verificar a influência das ligações de hidrogênio em cada um dos grupos $\left(\mathrm{NO}_{2}\right.$ e $\mathrm{NH}_{2}$ ) separadamente, e se um grupo teria mais importância que o outro. Neste 
caso, vemos pouca diferença no deslocamento do espectro quando a PNA é doadora ou receptora das ligações de hidrogênio com a água. De acordo com os resultados, a inclusão das moléculas explícitas parece ter o mesmo efeito seja quando se encontram ligadas ao grupo $\mathrm{NH}_{2}$ ou quando estão ligadas ao grupo $\mathrm{NO}_{2}$.

As energias de transição da PNA em água normal também foram consideradas neste trabalho, e são agora mostradas na tabela 7.6. Os modelos de solvente novamente são o eletrostático e a inclusão de moléculas explícitas do solvente nos cálculos. As moléculas explícitas são aquelas do solvente que passaram no critério de formação de ligações de hidrogênio com a PNA. Os resultados para água normal também foram obtidos com o funcional CAM-B3LYP. O shift espectral é agora mais pronunciado. O resultado experimental de $0.98 \mathrm{eV}$ em água normal é bem superior ao valor de $0.24 \mathrm{eV}$ obtido no caso supercrítico. Nesta condição termodinâmica o resultado obtido com CAM-B3LYP é de $0.56 \mathrm{eV}$, representando cerca de $2 / 3$ do valor experimental.

Tabela 7.6: Transições eletrônicas calculadas para a PNA isolada e em água em condições normais de temperatura e pressão. As abreviações cp se referem à cargas pontuais e HB significa que as moléculas que são incluídas explicitamente as moléculas que formam ligações de hidrogênio. As moléculas explícitas são aquelas que respeitam o critério de formação das ligações de hidrogênio. Cálculos realizados utilizando o funcional CAM-B3LYP.

\begin{tabular}{ccc}
\hline \hline \multirow{2}{*}{ Metodologia } & \multicolumn{2}{c}{ Transição em nm (eV) } \\
\cline { 2 - 3 } & Calculado & Experimental [94, 32] \\
\hline \hline Isolada & $288(4.30)$ & $292(4.25)$ \\
PNA $+350 \mathrm{cp}$ & $325 \pm 7(3.82)$ & $380(3.26)$ \\
PNA $+\mathrm{HB}+350 \mathrm{cp}$ & $331 \pm 10(3.74)$ & $380(3.26)$ \\
\hline \hline
\end{tabular}

Assim como na água supercrítica, também verificamos o resultado para outros funcionais nos cálculos do espectro em água normal, os valores convergidos são mostrados na tabela 7.7. Os resultados fornecem a mesma tendência de deslocar os valores das energias, porém, melhor concordância para o shift é obtida novamente pelo 
funcional CAM-B3LYP. Para o funcional B3LYP, por exemplo, o valor convergido (100 configurações) é de $364 \pm 10 \mathrm{~nm}$ fornecendo um shift de $43 \mathrm{~nm}$, apresentando a metade do shift observado experimentalmente [32]. Em termos de energia o shift obtido por B3LYP e PBE0 são, respectivamente, $0.45 \mathrm{eV}$ e $0.48 \mathrm{eV}$.

O resultado experimental para a banda de absorção em água mostra que comparado ao caso supercrítico essa banda desloca para o azul por $71 \mathrm{~nm}$. Esse deslocamento de cerca de $0.75 \mathrm{eV}$ é apreciável e não é bem descrito por nenhum dos métodos tratados aqui. O melhor resultado é obtido por CAM-B3LYP e corresponde a $0.32 \mathrm{eV}$. Como pode ser visto das tabelas 7.4 e 7.6, para tratar a PNA em água, a utilização de mais moléculas parece ser necessário. No entanto, no caso supercrítico a utilização explícita das moléculas que fazem ligação de hidrogênio em um embedding eletrostático fornece bons resultados. Isto mostra que no caso da água supercrítica os resultados corroboram a interpretação experimental [32] para o efeito de bulk mas que este tem natureza essencialmente eletrostática.

Tabela 7.7: Valores das energias de transição da PNA em água normal calculadas com os funcionais CAM-B3LYP, B3LYP e PBE0.

\begin{tabular}{ccccc}
\hline \hline \multirow{2}{*}{ Metodologia } & \multicolumn{4}{c}{ Transição em nm (eV) } \\
\cline { 2 - 5 } & CAM-B3LYP & B3LYP & PBE0 & Exp. [94, 32] \\
\hline \hline Isolada & $288(4.30)$ & $321(3.86)$ & $309(4.01)$ & $292(4.25)$ \\
PNA $+350 \mathrm{cp}$ & $325 \pm 7(3.82)$ & $356 \pm 8(3.48)$ & $344 \pm 8(3.60)$ & $380(3.26)$ \\
PNA + HB $+350 \mathrm{cp}$ & $331 \pm 10(3.74)$ & $364 \pm 10(3.41)$ & $351 \pm 10(3.53)$ & $380(3.26)$ \\
\hline \hline
\end{tabular}

\subsection{PNA em $\mathrm{CO}_{2}$ supercrítico}

Nesta seção apresentamos o estudo do espectro da PNA em ambiente formado por $\mathrm{CO}_{2}$ (dióxido de carbono). O $\mathrm{CO}_{2}$ tem sido estudado de forma intensa nos últimos anos como uma solvente em condições supercríticas $[1,12,15]$. Seu ponto crítico é atingido a uma temperatura relativamente baixa $\left(304 \mathrm{~K}\right.$ ou $\left.31^{\circ} \mathrm{C}\right)$ comparado à 
água, e o torna atraente do ponto de vista de manipulação experimental. Outras características que o torna interessante como solvente são: pode ser liquefeito a pressões relativamente baixas, é praticamente não tóxico e inerte, é não inflamável e de custo acessível [113]. Estas características também o tornam bem recebido para o uso industrial, na indústria química, farmaceutica e de alimentos [14]. Estudos sobre a solubilidade de vários compostos orgânicos em $\mathrm{CO}_{2}$ mostram o interesse do $\mathrm{CO}_{2}$ como solvente [23]. A utilização de sondas solvatocrômicas em estudos do espectro UV-visível também se apresenta em vários trabalhos para a determinação de parâmetros de escalas de solvente para caracterizar a polaridade do $\mathrm{CO}_{2}[21,23$, $24,114]$.

O espectro da PNA em $\mathrm{CO}_{2}$ foi medido experimentalmente a diferentes densidades [114], em torno do intervalo de $0.5-0.9 \mathrm{~g} / \mathrm{cm}^{3}$, que corresponde ao líquido até a condição supercrítica. Os valores do ponto crítico do $C O_{2}$ são: $T_{c}=304 \mathrm{~K}$, $P_{c}=74 \mathrm{~atm}$ e $\rho=0.46 \mathrm{~g} / \mathrm{cm}^{3}$.

\subsubsection{Simulação MC da PNA em $\mathrm{CO}_{2}$ supercrítico}

Utilizamos na simulação MC os parâmetros e cargas propostas em [115], que reproduzem bem os valores experimentais do ponto crítico do $\mathrm{CO}_{2}$, propriedades estruturais e outras propriedades termodinâmicas como curvas de coexistência líquidovapor. Os parâmetros $\varepsilon$ e $\sigma$ e as cargas utilizados no termo de Lennard-JonesCoulomb são apresentados na tabela 7.8. A simulação foi feita à temperatura de $315 \mathrm{~K}$ e densidade $\rho=0.81 \mathrm{~g} / \mathrm{cm}^{3}$ no ensembe NVT. Esta densidade escolhida por nós está no intervalo onde se encontram os resultados experimentais que utilizamos para comparação com nossos cálculos.

A geometria da PNA foi otimizada sob efeito do modelo contínuo polarizável (PCM), onde utilizamos constante dielétrica de valor $\epsilon=1.5$, pois este é o valor experimental determinado em [116] para condições de temperatura e densidade si- 
Tabela 7.8: Valores dos parâmetros do potencial desenvolvido para o $\mathrm{CO}_{2}$ [115]. A carga (em unidades atômicas) é a do átomo de carbono, as do oxigênio são negativas de modo a resultar em carga total nula para a molécula. A distância $l_{C-O}$ é o comprimento de ligação entre o átomo de carbono e os dois oxigênios.

\begin{tabular}{|c|c|c|c|c|c|}
\hline$\varepsilon_{C-C}(\mathrm{kcal} / \mathrm{mol})$ & $\sigma_{C-C} \quad(\AA)$ & $\varepsilon_{O-O}(\mathrm{kcal} / \mathrm{mol})$ & $\sigma_{O-O} \quad(\AA)$ & $q_{C} \quad(\mathrm{u} . \mathrm{a})$ & $l_{C-O} \quad(\AA)$ \\
\hline 0.057 & 2.7918 & 0.164 & 3.0 & 0.5888 & 1.163 \\
\hline
\end{tabular}

milares à utilizadas na simulação. As cargas atômicas também foram obtidas em PCM com o ajuste CHELPG, onde utilizamos a constante dielétrica de valor citado acima para a polarização do soluto. Estas cargas são mostradas na tabela 7.9 e mostram claramente que a polarização eletrônica da PNA devido ao solvente é bem inferior que no caso da água supercrítica. A função de distribuição radial de pares

Tabela 7.9: Cargas atômicas (em unidades atômicas) da PNA isolada e polarizada; abaixo estão os valores do momento de dipolo (em Debye). As cargas foram obtidas utilizando o método CHELPG em PCM, a constante dielétricas indicada em parênteses.

\begin{tabular}{ccc}
\hline \hline Átomo & Isolada & PCM $(\epsilon=1.5)$ \\
\hline C1 & -0.212926 & -0.229558 \\
C2 & 0.155520 & 0.153927 \\
C3 & -0.212926 & -0.229558 \\
C4 & -0.134627 & -0.125119 \\
C5 & 0.290608 & 0.284311 \\
C6 & -0.134627 & -0.125119 \\
N7 & 0.529510 & 0.561591 \\
O8 & -0.365615 & -0.386789 \\
O9 & -0.365615 & -0.386789 \\
H10 & 0.144138 & 0.152808 \\
H11 & 0.132070 & 0.135555 \\
H12 & 0.132070 & 0.135555 \\
H13 & 0.144138 & 0.152808 \\
N14 & -0.723124 & -0.743095 \\
H15 & 0.310703 & 0.324736 \\
H16 & 0.310703 & 0.324736 \\
$\mu(D)$ & 6.16 & 6.68 \\
\hline \hline
\end{tabular}


entre a PNA e as moléculas de $\mathrm{CO}_{2}$ calculada na simulação fornece o número de coordenação na primeira camada de solvatação em torno da PNA. A $g(r)$ mostrada na figura 7.10 é a de mínima distância (MDDF) [117] entre a PNA e as moléculas de $\mathrm{CO}_{2}$. A integração da curva sob o primeiro pico nesta $g(r)$ fornece o número de coordenação, que é de 17 moléculas de $\mathrm{CO}_{2}$ na primeira camada de solvatação.

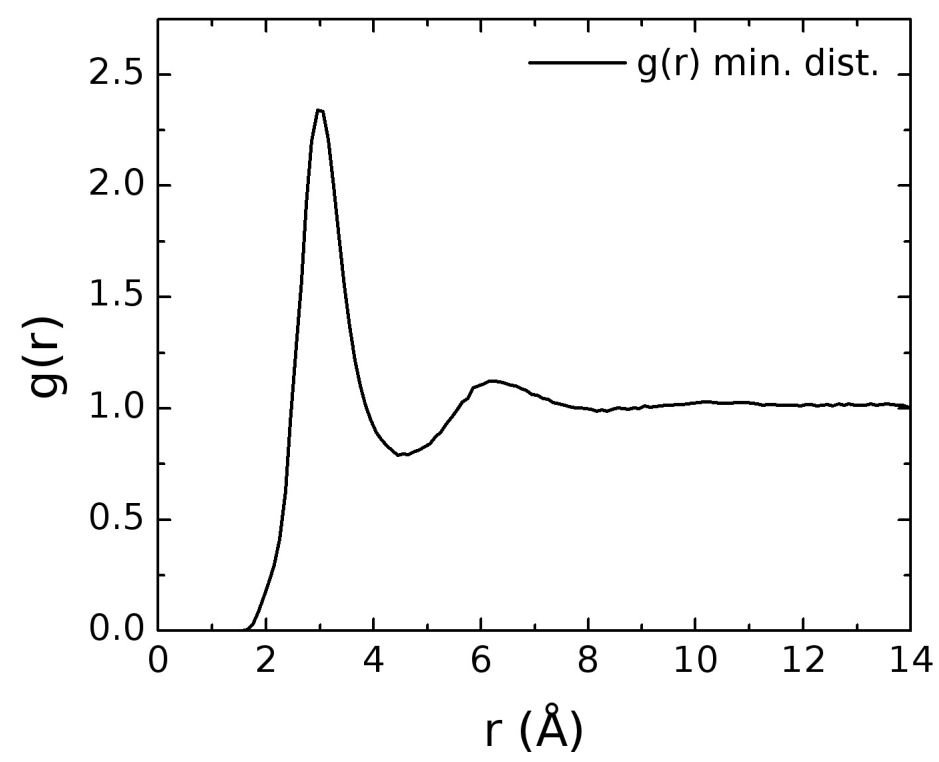

Figura 7.10: Função de distribuição de minima distância entre a PNA e o $\mathrm{CO}_{2}$. $O$ número de coordenação fornece 17 moléculas de $\mathrm{CO}_{2}$ na primeira camada de solvatação em torno da PNA. 


\subsubsection{Espectro da PNA em $\mathrm{CO}_{2}$ supercrítico}

Após a simulação, foram separadas as configurações estatísticamente descorrelacionadas para os cálculos de espectro eletrônico. Primeiro o efeito de solvente causado pelo $\mathrm{CO}_{2}$ foi incluído somente através da interação eletrostática (usando o solvente apenas como cargas pontuais nos sítios atômicos). Em seguida incluímos algumas moléculas explícitas envolvidas pelas cargas pontuais do $\mathrm{CO}_{2}$ usando as cargas mostradas na tabela 7.9, formando o embedding eletrostático. A partir da função de distribuição de mínima distância entre a PNA e o $\mathrm{CO}_{2}$ nós determinamos a quantidade de moléculas que seriam incluídas explicitamente nos cálculos quânticos. Optamos por incluir 12 moléculas, pois a inclusão de todas as moléculas da primeira camada de solvatação (17 no total) tornaria os cálculos bastante custosos. Com esta escolha, no entanto, obtivemos uma distribuição aproximadamente uniforme em torno da PNA como pode ser visto na figura 7.11.

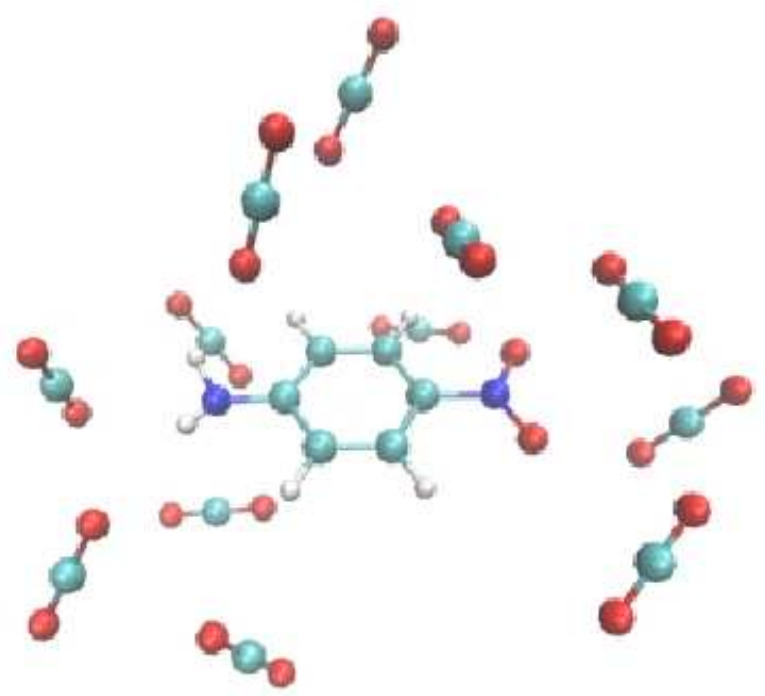

Figura 7.11: Ilustração de uma configuração obtida da simulação $M C$ da PNA em $\mathrm{CO}_{2}$. 
A tabela 7.10 mostra os valores obtidos considerando o embedding eletrostático, e em seguida calculamos acrescentando as doze moléculas explícitas de solvente. A figura 7.12 mostra a convergência do resultado, e em torno de 80 configurações já obtemos boa convergência. Apesar de ter sido considerado um número mais generoso de moléculas para o cálculo do espectro, vemos que considerar as cargas pontuais ainda fornece a maior contribuição para o deslocamento do espectro.

O deslocamento ou shift experimental é de $26 \mathrm{~nm}$, praticamente o dobro do obtido no espectro calculado $(12 \mathrm{~nm})$ incluindo as moléculas explícitas. O modelo eletrostático (apenas cargas pontuais) fornece um shift de $6 \mathrm{~nm}$.

Utilizando também outros dois funcionais para o cálculo do espectro e o efeito de solvente do modelo eletrostático (somente cargas pontuais). Verificamos que o funcional B3LYP fornece o valor convergido para a energia de $328 \mathrm{~nm}$, mas que corresponde a um shift de $7 \mathrm{~nm}$ em relação à molécula isolada. O funcional PBE0 apresenta o resultado $315 \mathrm{~nm}$ para a energia, o que corresponde a um shift de $7 \mathrm{~nm}$. Portanto, vemos que para o modelo eletrostático os funcionais apresentam praticamente a mesma descrição do efeito do solvente para o caso do $\mathrm{CO}_{2}$.

Tabela 7.10: Transições eletrônicas calculadas para a PNA isolada e em $\mathrm{CO}_{2}$ supercrítico. Espectro calculado utilizando TD-DFT e na combinação funcional/base CAM-B3LYP/aug-ccpVDZ. Os resultados são para a molécula isolada e efeito do solvente para modelo eletrostático e incluindo moléculas explícitas.

\begin{tabular}{ccc}
\hline \hline \multirow{2}{*}{ Metodologia } & \multicolumn{2}{c}{ Transição em nm (eV) } \\
\cline { 2 - 3 } & Calculado & Experimental [94, 114] \\
\hline \hline Isolada & $288(4.30)$ & $292(4.25)$ \\
PNA $+350 \mathrm{cp}$ & $294 \pm 3(4.22)$ & $318(3.90)$ \\
$\mathrm{PNA}+12 \mathrm{CO}_{2}+350 \mathrm{cp}$ & $300 \pm 5(4.13)$ & $318(3.90)$ \\
\hline \hline
\end{tabular}




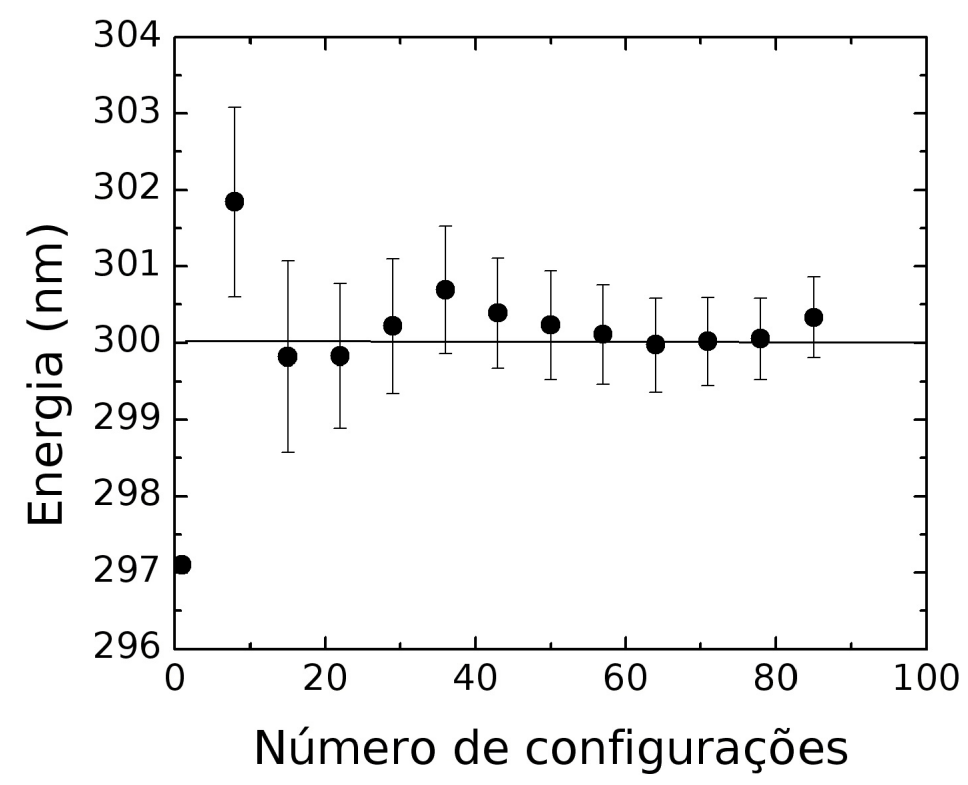

Figura 7.12: Convergência do espectro da PNA em $\mathrm{CO}_{2}$ calculado considerando a inclusão de 12 moléculas explícitas de $\mathrm{CO}_{2}$ mais as 350 moléculas representadas por cargas pontuais.

Como um sumário deste capítulo, descrevemos as seguintes conclusões: primeiramente a simulação MC da PNA em água supercrítica mostrou um decréscimo significativo para a ocorrência das ligações de hidrogênio entre a PNA e a água em relação à simulação em água normal. Estas ligações, portanto, ainda persistem nas condições supercríticas, como foi verificado pela aplicação do critério de formação da ligações.

No estudo do espectro eletrônico em água supercrítica, verificamos que o melhor resultado foi obtido pelo modelo eletrostático com a inclusão das moléculas de água que formam ligações de hidrogênio com a PNA explicitamente. Porém, a maior parte do red shift (tabela 7.4) é descrita quando apenas o modelo eletrostático é usado. Em água normal o método não obteve o mesmo sucesso, pelo menos dentro do mesmo procedimento adotado para água supercrítica, e pode ser necessário a 
inclusão de um maior número de moléculas explícitas.

O estudo do espectro da PNA em $\mathrm{CO}_{2}$ mostrou que a utilização de um número maior de moléculas explícitas não apresenta maior concordância com o espectro medido. O modelo eletrostático ainda corresponde à maior contribuição para o deslocamento do valor médio calculado. Porém, trata-se de um solvente muito diferente da água, principalmente no aspecto de o $\mathrm{CO}_{2}$ ser uma molécula apolar. O modelo eletrostático neste caso não apresenta a mesma eficiência como na água supercrítica. 


\section{Capítulo 8}

\section{Conclusões}

Neste capítulo reunimos as conclusões sobre os trabalhos apresentados nesta tese. Tivemos como objetivo estudar propriedades de estrutura eletrônica sob influência do meio líquido em especial na fase supercrítica. Utilizamos a metodologia sequencial, combinando simulações Monte Carlo e cálculos de mecânica quântica para tratar sistemas atômicos e moleculares e suas propriedades, tais como; polarizabilidade estática, ligações de hidrogênio, energias de transição e seu desvio espectral.

No primeiro estudo apresentamos o cálculo da polarizabilidade estática do átomo de argônio em fase líquida. Nossos resultados mostraram que ocorre um aumento na polarizabilidade em fase condensada. A constante dielétrica calculada a partir desta polarizabilidade está em ótima concordância com o valor experimental. Porém, ao estudarmos a variação da pressão sobre o sistema, observamos que a polarizabilidade se mostrou praticamente inalterada. Notamos também que a densidade pouco variou no intervalo de pressões que consideramos. As funções de distribuição radial de pares obtidas nas simulações indicam que a estrutura do líquido pouco se modificou, no sentido de que as camadas de solvatação foram pouco afetadas pelo efeito da pressão. Quando estudamos as condições de fluido supercrítico a polarizabilidade apresentou dependência com a densidade. Foram consideradas duas situações, onde 
a polarizabilidade se mostrou sensível à variação da densidade, diminuindo junto com a densidade. A polarizabilidade no ponto crítico foi calculada, apresentando menor valor que a que foi calculada em fase condensada. Conhecendo a polarizabilidade no ponto crítico, tivemos a possibilidade então de obter a constante dielétrica no ponto crítico, e que também apresentou uma diminuição em relação ao argônio líquido.

Em seguida, apresentamos o trabalho sobre $X e / A r$. Através das simulações Monte Carlo, obtemos as estruturas do fluido composto de um átomo de xenônio tratado como impureza imerso num ambiente formado por átomos de argônio. Exploramos os casos de baixa, moderada e altas densidades, e conseguimos descrever bem o comportamento do deslocamento espectral do Xe para a transição da absorção ${ }^{1} S \rightarrow{ }^{1,3} P$ nas diferentes condições termodinâmicas consideradas. Nossos resultados se concentraram mais nas transições dos estados tripleto $P\left({ }^{3} P\right)$. Há diferentes componentes do ${ }^{3} P$ correspondentes a $J=2,1,0$. Entretanto, as bandas experimentais em todas as condições termodinâmicas consideradas não apresentam resolução entre as possíveis componentes dos estados $P$. Portanto a falta de resolução experimental acabou por justificar a não separação destas componentes nos cálculos teóricos.

O estudo da paranitroanilina em água supercrítica mostrou que houve uma significativa redução na quantidade de ligações de hidrogênio que se formaram entre a PNA e as moléculas de água. Estas ligações, embora reduzidas, ainda são observadas em uma certa quantidade de configurações como se verificou nas simulações MC e na análise estatística. Esta conclusão é reforçada pela comparação com as simulações do mesmo sistema em água nas condições normais. Utilizando configurações estatisticamente descorrelacionadas, conseguimos descrever muito bem o shift experimental em água supercrítica. Nosso melhor resultado foi obtido pelas configurações contendo as ligações de hidrogênio em um embedding eletrostático. Observamos que a maior parte do deslocamento no espectro da PNA em água supercrítica foi des- 
crita quando usamos apenas o modelo eletrostático. Ao abordarmos o espectro da PNA em água normal observamos que não foi suficiente considerarmos o embedding mais as moléculas que fazem ligações de hidrogênio. O modelo eletrostático também mostrou descrever uma boa parte do delocamento do espectro, porém parece ser necessário considerar um maior número de moléculas explícitas, além daquelas mais próximas que fazem ligação de hidrogênio. O estudo do espectro da PNA em $\mathrm{CO}_{2}$ supercrítico mostrou que o modelo eletrostático forneceu resultados menos satisfatórios para este tipo de sistema. Mesmo incluindo os efeito de solvente com várias moléculas explícitas, os resultados tiveram pouca concordância quantitativa com o espectro medido, embora tenhamos obtido o deslocamento na direção correta. Notamos também que para o $\mathrm{CO}_{2}$, as interações eletrostáticas tem menor influência no deslocamento do espectro do que nos estudos da água. 


\section{Referências Bibliográficas}

[1] C. Reichardt, Solvents and Solvent Effects in Organic Chemistry, 4th Ed.. Wiley-VCH (2010).

[2] L. Onsager, J. Am. Chem. Soc. 58, 1486 (1936).

[3] J. G. Kirkwood, J. Chem. Phys. 2, 351 (1934).

[4] S. Miertuš, E. Scrocco, J. Tomasi, Chem. Phys. 55, 117, (1981).

[5] J. Tomasi, Theor. Chem. Acc. Phys. 112, 184, (2004).

[6] J. Tomasi, B. Mennucci et al, Chem. Rev. 105, 2999 (2005).

[7] A. Warshell and M. Levitt, J. Mol. Biol. 103, 227 (1976).

[8] H. Senn and W. Thiel, Top. Curr. Chem. 268, 173 (2007).

[9] H. Lin and D. Truhlar, Theo. Chem. Acc 117, 185 (2007).

[10] S. Canuto and K. Coutinho, Adv. Quantum Chem. 28, 29 (1997).

[11] S. Canuto and K. Coutinho, Int. J. Quantum Chem. 77, 192 (2000).

[12] P. Jessop and W. Leitner, Handbook of Green Chemistry, Volume 4: Supercritical Solvents. W. Leitner and W. Jessop (Eds.) Wiley-VCH, 1-30 (2010).

[13] C. A. Eckert, B. L. Knutson and P. G. Debenedetti, Nature 383, 313 (1996). 
[14] A. C. Furlan, F. W. Fávero, J. Rodriguez, D. Laria and M. S. Skaf, Solvation in Supercritical Fluids. In "Solvation Effects in Molecules and Biomolecules: Computational Methods and Applications"; S. Canuto (Eds.) Springer, 433-453 (2008).

[15] G. H. Brunner (Ed.), Supercritical Fluids as Solvents and Reaction Media. Elsevier (2004).

[16] O. Kajimoto, Chem. Rev. 99, 355 (1999).

[17] S. Tuker, Chem. Rev. 99, 391 (1999).

[18] K. Coutinho and S. Canuto, Sequential Monte Carlo/Quantum Mechanics study of the dipole polarizability of atomic liquids: The argon case, in "Atoms, Molecules and Clusters in Electric Fields. Theoretical Approaches to the Calculation of Electric Polarizabilities", G. Maroulis (Ed.), Imperial College Press, London, 405-420 (2006).

[19] K. Coutinho and S. Canuto, Sequential Monte Carlo and Quantum Mechanics Calculation of the Static Dielectric Constant Liquid Argon, in "Practical Aspects of Computational Chemistry, Concepts and Applications", J. Leszczynski and M. Shukla (Eds.) Springer Netherlands, 327-336 (2006).

[20] H. S. Nalwa and S. Miyata (Ed.), Nonlinear Optics of Organic Molecules and Polymeric Materials, CRC Press (1997).

[21] Y. Marcus, J. Phys. Org. Chem. 18, 373 (2005).

[22] S. Kim and K. P. Johnston, Ind. Eng. Chem. Res. 26, 1206 (1987).

[23] J. Hyatt, J. Org. Chem. 49, 5097 (1984).

[24] M. Maiwald and G. M. Schneider, Ber. Bunsenges. Phys. Chem. 102, 960 (1998). 
[25] C. R. Yonker, S. L. Frye, D. R. Kalkwarf and R. D. Smith, J. Phys. Chem. 90, $3022(1986)$.

[26] Y. Marcus, Phys. Chem. Chem. Phys. 2, 1465 (2000).

[27] A. G. Kalinichev and J. D. Bass, Chem. Phys. lett. 231, 301 (1994).

[28] Y. E. Gorbaty and A. G. Kalinichev, J. Phys. Chem. 99, 5336 (1995).

[29] A. G. Kalinichev and J. D. Bass, Chem. Phys. Lett. 231, 301 (1994).

[30] T. L. Fonseca, K. Coutinho and S. Canuto, Phys. Chem. Chem. Phys. 12, 6660 (2010).

[31] T. L. Fonseca, K. Coutinho and S. Canuto, J. Chem. Phys. 126, 034508 (2007).

[32] H. Oka and O. Kajimoto, Phys. Chem. Chem. Phys. 5, 2535 (2003).

[33] Allen, M. P. and D. J. Tildesley; Computer Simulation of Liquids, Clarendon Press (1987).

[34] J. D. M. Vianna, A. Fazzio e S. Canuto, Teoria Quântica de Sólidos e Moleculas - Simulação Computacional. Livraria da Física, São Paulo (2004).

[35] N. Metropolis, A. W. Rosenbluth, M. N. Rosenb, A. H. Teller and E. Teller, J. Chem. Phys. 21, 1087 (1953).

[36] A. Eisenstein and N. S. Gingrich, Phys. Rev. 58, 307 (1940).

[37] A. Eisenstein and N. S. Gingrich, Phys. Rev. 62, 261 (1942).

[38] J. L. Yarnell, M. J. Katz and R. G. Wenzel, Phys. Rev. A 7, 2130 (1973).

[39] K. Coutinho; Modelo Discreto de solvente. Solvatocromismo no Espectro de Absorção Molecular, Tese de Doutorado - USP, (1997). 
[40] A. Szabo and N. Ostlund, Modern Quantum Chemistry - Introduction to Advanced Electronic Structure, Dove Publications Inc. (1996).

[41] I. N. Levine, Quantum Chemistry, Prentice Hall, Upper saddle river, NJ (2009).

[42] D. C. Young, Computational Chemistry, John Wiley \& Sons (2001).

[43] F. Jensen, Introduction to Computational Chemistry. John Wiley \& Sons (2007).

[44] M. Born and J. R. Oppenheimer, Ann. Phys. 84, 457 (1927).

[45] J. C. Slater, Phys. Rev. 34, 1293 (1929).

[46] J. A. Pople and D. L. Beveridge, Aproximate Molecular Orbital Theory, McGraw-Hill (1970)

[47] C. C. J. Roothaan, Rev. Mod. Phys. 23, 69 (1951).

[48] J. C. Slater, Phys. Rev. 36, 57 (1930).

[49] S. F. Boys, Proc. Roy. Soc. A 200, 542 (1950).

[50] W. J. Hehre, L. Radom, P. v. P. Schleyer and J. A. Pople, Ab Initio Molecular Orbital Theory, Jonh Wiley \& Sons (1986).

[51] C. J. Cramer, Essentials of Computational Chemistry - Theories and Models, John Wiley \& Sons (2004).

[52] C. Møller e M. S. Plesset, Phys. Rev. 46, 618 (1934).

[53] P. Hohenberg and W. Kohn, Phys. Rev. 136, B864 (1964).

[54] W. Kohn, A. D. Becke and R. G. Parr, J. Phys. Chem. 100, 12974 (1996).

[55] K. Capelle, A Bird's View of Density-Functional Theory, Escola Brasileira de Estrutura Eletrônica, Juiz de Fora, Ed. Livraria da Física, 2002, pp. 1-37. 
[56] W. Kohn and L. J. Sham, Phys. Rev. 140, A1133 (1965).

[57] A. D. Becke, J. Chem. Phys. 98, 5648 (1993).

[58] J. P. Perdew, Phys. Rev. B 33, 8822 (1986).

[59] C. Lee, W. Yang and R. G. Parr, Phys. Rev. B, 37, 785 (1998).

[60] E. Runge and E. K. U. Gross, Phys. Rev. Lett. 52, 997 (1984).

[61] A. Dreuw and M. Head-Gordon, Chem. Rev. 105, 4009 (2005).

[62] M. A. L. Marques and E. K. U. Gross, Time Depedent Functional Theory, in "A Primer in Density Functional Theory". F. Fiolhais, F. Nogueira and M. Marques (Eds.), Springer-Verlag, Berlin Heidelberg (2003).

[63] K. Coutinho, R. Rivelino, H. C. Georg and S. Canuto, The Sequential QM/MM Method and Its Application to Solvent Effects in Electronic and Structural Properties of Solutes. In "Solvation Effects in Molecules and Biomolecules: Computational Methods and Applications"; Canuto S (Eds.) Springer, 159-189 (2008).

[64] H. C. Georg e S. Canuto, Métodos Híbridos para Modelagem do Ambiente Molecular, em "Métodos de Química Teórica e Modelagem Molecular". N. Morgon e K. Coutinho (Ed.), Editora Livraria da Física, 453-488 (2007).

[65] K. Coutinho and S. Canuto, DICE (version 2.9): A general Monte Carlo program for liquid simulation, Universidade de São Paulo (2009).

[66] C. Bistafa, Efeito de Solvente no Espectro de Absorção da 5-Fluorouracil. Análise de Diferentes Procedimentos Teóricos. Dissertação de Mestrado - USP (2011). 
[67] D. C. Harris and M. D. Bertolucci, Symmmetry and Spectroscopy - An Introduction to Vibrational and Electronic Spectroscopy. Dover Publications Inc. (1989).

[68] A. Morita and S. Kato, J. Chem. Phys. 110, 11987 (1999).

[69] P. Th. van Duijnen, A. H. de Vries, M. Swart and F. Grozema, J. Chem. Phys. 117, 8442 (2002).

[70] S. Canuto, K. Coutinho and P. Mukherjee, Adv. Quantum Chem. 48, 141 (2005).

[71] G. Maroulis, J. Chem. Phys. 113, 1813 (2000).

[72] K. V. Mikkelsen, Y. Luo, H. Ågren and P. Jorgensen, J. Chem. Phys. 102, 9362 (1995).

[73] G. C. Maitland and E. B. Smith, Mol. Phys. 22, 861 (1971).

[74] R. B. Stewart and R. T. Jacobsen, J. Chem. Phys. Ref. Data 18, 639 (1989).

[75] A. Eisenstein and N. S. Gingrich, Phys. Rev. 62, 261 (1942).

[76] D. E. Woon and T. H. Dunning Jr, J. Chem. Phys. 98, 1358 (1993).

[77] D. R. Lide, Ed., CRC HandBOOK of Chemistry and Physics, 73rd Edition. CRC Press, Boca Raton (1993).

[78] D. R. Johnston, G. J. Oudemans and R. H. Cole, J. Chem. Phys. 33, 1310 (1960).

[79] M. J. Frisch et al., Gaussian 03, Revision D.01, Gaussian, Inc. Wallingfort CT (2004).

[80] H. Frölich, Theory of Dielectrics. Clarendon Press, Oxford (1958). 
[81] R. K. Teague, C. J. Pings, J. Chem. Phys. 48, 4973 (1968)

[82] I. Messing, B. Raz and J. Jortner, J. Chem. Phys. 66, 2239 (1977)

[83] B. Raz and J. Jortner, Proc. R. Soc. A, 317, 113 (1970).

[84] J. M. Rupim, M. Morlais and S. Robin, C. R. Acad. Sci. Ser. B 265, 1177 (1967).

[85] M. Hidalgo, S. Canuto, Physics Letters A 377, 1720 (2013).

[86] L. Verlet and J. J. Weiss, Mol. Phys. 24, 1013 (1972).

[87] Y. Takahashi, K. Sano, T. Kinoshita and T. Yabuzaki, Phys. Rev. Lett. 71, 1035 (1993).

[88] F. Dalfovo, Z. Phys. D 29, 61 (1994).

[89] P. Fuentealba, H. Preuss, H. Stoll and L. v. Szentpaly, Chem. Phys. Lett. 89, 418 (1982).

[90] A. Nicklass, M. Dolg, H. Stoll and H. Preuss, J. Chem. Phys. 102, 8942 (1995).

[91] M. J. Frisch et al., Gaussian 09, Revision A.1, Gaussian, Inc. Wallingfort CT (2009).

[92] S. Grimme, J. Comp. Chem. 27, 1787 (2006).

[93] J. -D. Chai and M. Head-Gordon, Phys. Chem. Chem. Phys. 10, 6615 (2008).

[94] S. Millefiori, G. Favini, A. Millefiori and D. Grasso, Spectrochim. Acta 102, $9362(1995)$.

[95] M. B. Ledger and P. Suppan, Spectrochim. Acta 33A, 21 (1977). 
[96] V. M. Farztdinov, R. Schanz, S. A. Kovalenko and N. P. Ernsting, J. Phys. Chem. A 104, 11486 (2000).

[97] C. L. Thomsen, J. Thøgersen and S. R. Keiding, J. Chem. Phys. A 102, 1062 (1998).

[98] S. A Kovalenko, R. Schanz, V. M. Farztdinov, H. Hennig and N. P. Ernsting, Chem. Phys. Lett. 323, 312 (2000).

[99] H. J. C. Berendsen, J. R. Griegera and T. P. Straatsma, J. Phys. Chem. 91, 6269 (1987).

[100] Y. Guissani and B. Guillot, J. Chem. Phys. 98, 8221 (1993).

[101] W. L. Jorgensen, D. S. Maxwell and Tirado-Rives, J. Am. Chem. Soc. 118, 11225 (1996).

[102] H. Reis, M. G. Papadopoulos and A. Gryzbowski, J. Phys. Chem. B 110, 18537 (2006).

[103] D. G. Archer and P. Wang, J. Phys. Ref. Data 19, 371 (1990).

[104] M. Uematsu and E. U. Franck, J. Phys. Chem. Ref. Data 9, 1291 (1980).

[105] C. S. Pomelli and J. Tomasi, J. Chem. Phys. A 101, 3561 (1997).

[106] C. M. Breneman and K. B. Wiberg, J. Comput. Chem. 11, 361 (1990).

[107] A. Botti, F. Bruni, M. A. Ricci and A. K. Soper, J. Chem. Phys. 109, 3180 (1998)

[108] G. E. Bennett and K. P. Johnston, J. Phys. Chem. 98, 441 (1994).

[109] R. Mountain, J. Chem. Phys. 90, 1866 (1989). 
[110] T. Yanai, D. Tew and N. Handy, Chem. Phys. Lett. 393, 51 (2004).

[111] J. P. Perdew, K. Burke and M. Ernzerhof, Phys. Rev. Lett. 77, 3865 (1996).

[112] C. Adamo and V. Barone, J. Chem. Phys. 110, 6158 (1999).

[113] E. J. Beckman, J. of. Supercritical Fluids 28, 121 (2004).

[114] M. E. Sigman, S. M. Lindley and J. E. Leffler, J. Am. Chem. Soc. 107, 1471 (1985).

[115] Z. Zhang and Z. Duan, J. Chem. Phys. 112, 214507 (2005).

[116] A. Wesch, N. Dahmen and K. H. Ebert, Ber. Bunsenges Phys. Chem. 100, 1368 (1996).

[117] S. Canuto, K. Coutinho and D. Trzesniak, Adv. Quantum Chem. 41, 161 $(2002)$ 